

Zurich Open Repository and Archive

University of Zurich

University Library

Strickhofstrasse 39

CH-8057 Zurich

www.zora.uzh.ch

Year: 2015

\title{
Verleugnung der Wortkunst als Bekenntnis
}

Stotz, Peter

Posted at the Zurich Open Repository and Archive, University of Zurich

ZORA URL: https://doi.org/10.5167/uzh-131436

Book Section

Originally published at:

Stotz, Peter (2015). Verleugnung der Wortkunst als Bekenntnis. In: Kössinger, N; Krotz, E; Müller, S. Ekkehart IV. von St. Gallen. Berlin, Boston: De Gruyter, 393-419. 


\title{
Peter Stotz \\ Verleugnung der Wortkunst als Bekenntnis
}

\author{
Zu den drei confutatio-Gedichten Ekkeharts IV. von St. Gallen
}

\section{Zur Einführung}

\subsection{Ekkehart als Liebhaber antiker Bildung}

Ekkehart IV. ${ }^{1}$ ist, was die überkommene Bildung angeht, nicht als Kostverächter bekannt. In seinem Geschichtswerk und in seinen Dichtungen entdecken wir allenthalben Anspielungen auf antike Schriftsteller, auf die staatlichen, rechtlichen und kulturellen Verhältnisse der Römerzeit, erkennen wir die Anwendung dessen, was man damals an sprachlich-literarischen Fertigkeiten zum eigenen Gebrauch erlernte - kurz: werden wir seiner höchst beachtlichen Bildung gewahr. Über die rhetorisch-dichterischen Ausdrucksmittel schrieb er seinem Bruder Ymmo ein kleines Lehrgedicht de lege dictamen ornandi. ${ }^{2}$ Zeitlebens hat Ekkehart sich um wirkungsvolles Schreiben bemüht: seine Geschichte des Gallusklosters ist unmittelbar packend. Seine Dichtungen im Liber Benedictionum entsprechen zwar gewiss nicht unseren ästhetischen Idealen, zeugen jedoch auf ihre Weise von einem entwickelten Formensinn und dem Willen zu eigener Kunstausübung nach hergebrachten Kategorien. Wenn Ekkehart nun gerade darin (Benedictiones [...] per circulum anni, in den Gedichten 40 bis 42) den drei Disziplinen, welche zur Ordnung der Gedanken und zur Meisterung der Sprache anleiten, je eine confutatio, eine Widerrede entgegensetzt, ihnen die Gefolgschaft verweigert, so mag das auf den ersten Blick überraschen.

\footnotetext{
1 Den behandelten Gedichten selber liegt zugrunde deren Edition in: Ekkehart, Liber Benedictionum/ Egli 1909, 206-208 (Ekkeh. IV. bened. I 40)/208-210 (41)/211-217 (42). In Ekkeharts Autograph, der St. Galler Handschrift 393, finden sie sich auf den Seiten 142f./143-145/146-150. - An Literatur seien vorab genannt: Schulz 1942 und Weber 2003.- Alle erwähnten St. Galler Handschriften sind als Digitalisate zugänglich unter Codices electronici Sangallenses, http://www.cesg.unifr.ch/de/index.htm. - Die Angabe angeführter Textstellen richtet sich, soweit möglich, nach den Zitierlisten des ThLL, des MLW und des NGML, wo auch die maßgebenden Editionen nachgewiesen sind.
}

2 Ekkeh. IV. carm. var. II 1, MGH Poetae 5, 532f. 


\subsection{Diskurstradition der christlichen Einfachheit}

Aber gerade auch hiermit bewegt sich Ekkehart auf gebahnten Pfaden, er schlüpft in eine Rolle, die sich manche vor und nach ihm zu eigen gemacht haben, ja, man könnte sagen: in eine Rolle, die ihm auferlegt war. In der Tat stand es einem gebildeten Christen der Zeit wohl an, sich in die - damals seit langem gepflegte und in der Forschung viel besprochene - Diskurstradition des sermo humilis einzureihen, sich zu der Fischersprache der einfachen Jünger Christi zu bekennen. ${ }^{3}$ Vielleicht ist es gar ein Kennzeichen der Geistigkeit in hochmittelalterlichen monastischen Kreisen und deren Umgebung, sich um hohe Bildung und Rationalität zwar zu mühen, aber gleichzeitig Skepsis dagegen zu nähren. Dabei hatte nicht jeder die inneren Kämpfe eines Otloh von St. Emmeram (um 1010 - kurz nach 1079) auszufechten ${ }^{4}$. Bei manchen mochte diese Absage an die Traditionen der Antike, dieses SichAnschmiegen an die gemeine Rede von gebotener christlicher Einfachheit einem Augenblick der Besinnung vorbehalten sein, ohne das eigene Leben und Streben allzu nachhaltig zu bestimmen.

\subsection{Schülerdichtung für Notker den Deutschen}

Ekkehart musste zu dieser Vorstellung und Haltung nicht erst durch ausgedehnte Lektüre christlichen Schrifttums gelangen, denn gewiss hatte sie sein Lehrer Notker schon früh an ihn herangetragen: Er scheint es darauf angelegt zu haben, bei den begabtesten unter seinen Schülern den Sinn zu wecken für das heikle Gleichgewicht zwischen der Aneignung der pagan-antiken Bildungsgüter und der gebotenen Abstandswahrung von ihnen. Dies wohl schon in seinen Lehrvorträgen, dann aber auch so, dass er Ekkehart dazu anhielt, in den Dichtübungen, die er ihm auferlegte, diese Gedanken zu gestalten. Denn die Confutatio rhetorice, oder jedenfalls deren Eingangspartie, hatte einem dichterischen Tagewerk des Schülers entsprochen, und bei der Confutatio grammatice sind (ungefähr) die letzten zwei Drittel als drei Tagespensen - von ungleicher Länge - ausgewiesen. ${ }^{5}$ Ob allerdings die drei Gedichte, so wie sie uns autograph überliefert sind, in ihrem ganzen Umfang aus dem Schulunterricht hervorgegangen sind, oder ob Ekkehart sie erst später zu dem erweitert hat, als was sie uns entgegentreten, lässt sich kaum noch feststellen. Die Confutatio grammaticę enthält in ihrer Schlusspartie eine peroratio, die sich auf die drei Stücke insgesamt beziehen könnte. Damit ließe sich vielleicht auch erklären, warum die Grammatik, die in der Abfolge der artes gewöhnlich an der Spitze steht, im Liber

3 Vgl. Hagendahl 1959, Bambeck 1983.

4 Vgl. Schauwecker 1963, 52-240, Gäbe 1999, 159-178.

5 Vgl. Stotz 1981, 4. 
Benedictionum an den Schluss dieser Trias gesetzt ist. In allen drei Stücken ist die Benützung von De nuptiis Philologiae et Mercurii des Martianus Capella (wohl 2. Hälfte 5. Jh.) greifbar, am stärksten in Gedicht 41, der Absage an die Dialektik, wo keine Beischriften auf Entstehung in der Schule hinweisen. Gewiss hatte diese damals beliebte artes-Lehrschrift, deren zwei erste Bücher Notker ja auch schriftlich bearbeitet hat, in seinem Unterricht große Geltung.

\subsection{Zum Begriff der confutatio}

Wenn bei Martianus Capella diese drei artes als weibliche Personifizierung vor die Götterversammlung treten, so könnte man sich gut vorstellen, dass auch Ekkehart seine drei Gegnerinnen sich als allegorische Frauenspersonen vorstellt. Confutatio ,Widerlegung' ist ein Terminus der Rhetorik, und nach einem Zeugnis Donats (um 310-380) wird dieses Wort dann gebraucht, wenn sich die Widerrede gegen Personen richtet, während eine Widerlegung von Dingen refutatio heiße. Im patristischen Schrifttum ist etwa von confutatio haereticorum die Rede. ${ }^{6}$

\subsection{Zwei verschiedene confutationes}

Eine solche confutatio scheint mir nun in den drei Texten allerdings auf unterschiedliche Weise stattzufinden. In der Zurückweisung der Rhetorik und der Dialektik wird das Arsenal von deren Begriffen und Methoden benützt, lediglich anders angewandt: Man bekämpft Unglauben und Gottlosigkeit mit eben den Waffen, die man der Gegnerin entwunden hat. So macht denn Ekkehart die Begrifflichkeit dieser Disziplinen in heilsgeschichtlich-pastoralem Sinne nutzbar. Diese Denkfigur ist in der christlichen Bildungsapologetik allgegenwärtig, etwa in der stehenden Rede von der spoliatio Aegyptiorum. In der Absage an die Grammatik dagegen geht es, zumindest scheinbar, um rein Formales: Biblische und für spezifisch christlich gehaltene Spracheigentümlichkeiten werden gegen - echte oder vermeintliche - pagan-antike Normen verteidigt, dies im Verfolg des Projekts einer christlichen Grammatik, zu dem manche sich bekannt haben, mit dem aber niemand so richtig ernst gemacht hat. ${ }^{7}$ - Zunächst nun eine knappe Inhaltsangabe der drei Stücke:

6 Vgl. ThLL 4, 270, 67-81.

7 Vgl. Stotz 2011, 20-22. 


\section{Zum Gedankengang in den drei confutationes}

\subsection{Confutatio rhetorice}

Die Confutatio rhetoricę wird (V.1-7) eröffnet mit einer ausladenden Apostrophe an Satan als den Patron von Lug und Trug, dem die Rhetorik - mitunter - dient. Der klassischen Trias von deren drei Anwendungsgebieten wird, ohne dass dies näher reflektiert würde, die göttliche Dreifaltigkeit entgegengesetzt ${ }^{8}$. Aber zwei von ihnen, die Lob- und die Beratungsrede, interessieren unseren Dichter nicht, ihm geht es einzig um die Gerichtsrede - und um die übermächtig gewordene Ausstülpung der Rhetorik, nämlich die Rechtswissenschaft. Der Teufel ist, wie es ja das griechische Etymon seines Namens besagt, der Ankläger, der aber zuschanden wird. Ekkehart, an den Belangen des alten Römertums interessiert, handelt (V. 8-12) von den Rollen von Prätor und Zensor vor Gericht, so, wie er sie sieht. Ihm geht es um die abmildernde Umdeutung eines eingeklagten Tatbestandes durch den Richter. Dies wird nun (V.13-18) auf Anklage und Gericht vor Gott angewandt: Prätor ist, im Sinne einer Selbstanklage, der beichtende und bereuende Sünder oder aber Satan, der Verkläger der Brüder (Apoc. 12, 10), Zensor ist Gott oder Christus. Die Umwandlung des Tatbestandes wird einer Befreiung von Schuld gleichgesetzt. Dann (V.19-25) kommt die Rede darauf, es sei verpönt gewesen, als Angeklagter um Gnade zu bitten. Für ,uns‘ jedoch, die vor dem Richterstuhl Gottes Stehenden, sei dies ins Gegenteil verkehrt worden. Es folgt (V. 26-27) die Versicherung, dass ,wir‘ uns vor zünftigen, rhetorisch versierten Anklägern ebenso wenig zu fürchten hätten wie seinerzeit Paulus vor dem Anwalt Tertullus. Gleich danach (V. 28-34) wird der Gedanke weitergeführt, dass , wir' die Kraft des Gebetes erfahren dürften, und daher die Rhetoriker alten Schlages, hier gesehen in ihrer Rolle als Ankläger, ausgedient hätten.

\subsection{Confutatio dialectice}

Die Absage an die Dialektik wird (V.1-3) ihrerseits mit einer sozusagen dialektischen Gegenüberstellung eröffnet: derjenigen zwischen der Einführung des Neuplatonikers Porphyrios (ca. 234-305/310) in die aristotelische Logik und dem Heiligen Geist. Zwar selber ein Getaufter, habe Porphyrios die christliche Lehre bekämpft, statt sie für sein Tun nutzbar zu machen - was Ekkehart nun im umgekehrten Sinne, auf eine etwas eigenartige Weise, selber zu tun versucht: So wendet er (V. 4-6) den Subjektbegriff auf die Dreifaltigkeit an und setzt (V.7-10) die Zehnzahl der

8 Eine solche ganz im Äußerlichen verbleibende Trinitätsanalogie findet sich auch in Ekkeh. IV. cas. 51; dort geht es um den Fluss Sitter - mit lateinischem Namen(skonstrukt) Sinttriaunum -, den der heilige Gallus sanctę trinitatis amore so benannt habe. 
Kategorien mit einer - nicht näher bestimmten - dekadischen Reihe von Lehren des Evangeliums in Beziehung; im Vorübergehen erinnert er an die Zehn Gebote. Dann exerziert er (V.11-12) mit dem Terminus proloquium, und gleich darauf (V.13) gibt er mit dem Bekenntnis zum Trinitätsgeheimnis nach der geläufigen Formel trinus/unus ein Beispiel für eine praedicatio. Dies, um anschließend (V. 14-18) unter der Rubrik conditionale in Form einer bedingungsweisen Annahme des dreieinigen Gottes durch eine siebenfache Aussage dessen Wirken zu erweisen. Dann (V. 19-20) kommt er auf die dreiteilige Struktur des Syllogismus, der nach fünf Modi erfolge, zu sprechen. Dem syllogistischen Schließen gemäß den Regeln der Kunst (ars) stellt er (V. 21-24) geistgewirkte „Syllogismen“ gegenüber: Zunächst (V. 25-27) geht es um das Paradox der virgo/mater Maria, sodann (V. 28-30) um das glaubensmäßig $\mathrm{zu}$ erfassende Ineinssein der drei göttlichen Personen. Anschließend (V.31-34) kommt Ekkehart auf die Jungfrauengeburt zurück, indem er einen nach der menschlichen Logik vorauszusetzenden Satz im Namen des Glaubens entkräftet. Im Folgenden (V.35-37) stellt er zwei unterschiedliche Stile philosophischer Tätigkeit einander gegenüber, die er, etwas anfechtbar, auf den Wortsinn der Benennungen zweier philosophischer Schulen zurückführt: unter den Menschen umherzuwandeln oder aber, an Ort und Stelle zu meditieren. Diese Dichotomie ist für ihn (V. 38-40) christlicherseits überhöht durch die vita activa und die vita contemplativa, verkörpert durch die Schwestern Martha und Maria (vgl. Luc. 10, 38-42). Nach alledem gelangt er (V. 41-44) zu dem Schluss, die menschliche Logik sei durch die von oben kommende Weisheit durchkreuzt und entkräftet.

\subsection{Confutatio grammatice}

In der ausladenden Confutatio grammaticę, länger als die beiden andern Stücke zusammen, und auch dem Interpretationsbedarf nach aufwendiger als sie, stellt Ekkehart seine - oder die ihm von der Tradition vermittelte - Sicht einer spezifisch christlichen Handhabung der Sprache dar. Die einfache Sprache der Christen, vergegenwärtigt vor allem durch die lateinische Bibelübersetzung, stellt er paganantikem Wortgepränge entgegen. Dabei werden allerlei sprachliche Eigenheiten, die sich - auch, aber nicht nur - in christlichen Texten finden, als christlich gekennzeichnet. Ekkehart geht (V.1-6) von der Figur der Grammatica bei Martianus Capella aus und beurlaubt sie gewissermaßen zugunsten der einfachen Sprache von Fischern gleich Petrus und mit Blick auf den oft ins Feld geführten Gedanken, dass die Sprache des Glaubens keine formalen Fesseln kenne. Das Gesagte führt er (V.7-15) am Beispiel der Briefe des Paulus vor, den er, in zeittypischer Verkürzung, zumindest mittelbar, zum Lateiner, nämlich zum Renegaten von Donats Lehren, macht. Anschließend (V. 16-21) stellt er, unter Nennung Bethsaidas, des Heimatdorfes der Brüder Petrus und Andreas, deren ,Fischersprache“ der urbanen Redeweise gegenüber. Dies mündet (V. 22f.) in den - für die Apologetik christlicher Redeweise typi- 
schen - Beizug des paulinischen Wortes vom Kreuz. Noch an weitere Bibelstellen und biblische Personen wird erinnert: an Jesu Lieblingsjünger Johannes (V. 24f.) und an die Rede von der Christusbrautschaft der (einfachen) Gläubigen (V. 26-30).

Dann folgt (V.31-39) ein Rückblick auf die Übersetzungen der heiligen Texte aus dem Hebräischen und dem Griechischen: ihre Schlichtheit habe durch den Umsetzungsvorgang nicht gelitten. Gerade Hieronymus (um 347-419) erachte (V. 38f.) das Regelwerk Priscians, der großen grammatischen Autorität der Spätantike (Ende 5./Anfang 6. Jh.) - jünger als er! - für unnütz. Nun folgen (V. 40-50) Beispiele für Nebenformen von Wörtern, die dank ihrem Vorkommen in christlichen Texten für geheiligt hingestellt werden: fodiri für fodi, ructare für ructuare, angustiare für angustare, weiter die Genitiv-Plural-Form duorum für (angeblich normales) duum, missa statt des pluralischen missae, auch melota für melotes oder -tis. Gegen weitere grammatische Autoritäten verteidigt er fraudare statt des angeblich regelkonformeren frudare und die Perfektform iuvavi(sse) statt des normalen iuvi(sse). All diese Beispiele betreffen inner-lateinische Varianten, und so mutet es seltsam an, dass Ekkehart eingangs (V. 40-42) die Formen, die er als christliche beansprucht, unter das Signum der Übersetzungstreue stellt, gerade so, als ob ihr Gebrauch durch den Urtext vorgegeben wäre ${ }^{9}$. Ferner beruft er sich (V. 50-53) auf die gottesdienstliche Gesangspraxis und führt Gregor den Großen (um 540-604) als Autorität hierfür an: die auf ihn zurückgeführten liturgischen Gesänge galten ja für unmittelbar inspiriert. Sodann hebt Ekkehart (V. 54-56) seine Beurteilungen ab von den Lehren jüngerer Grammatiker im Fahrwasser Donats.

Darauf (V.57-63) wirft er einen Blick auf die Kirchengeschichte: Die drei sprachbezogenen Disziplinen hätten der alten Kirche schwer geschadet, weil die Häretiker sich ihrer bedient hätten; als Protagonisten nennt er einerseits Arius (um 260-um 336), andererseits Athanasius (um 295-373). Zugleich mit der Fischersprache verhöhnten die Irrlehrer (V.64-67) die Kirche selber. Und nun (V.68-71) kommt er auf den Zwiespalt zu sprechen, in dem die christlichen Bildungsbeflissenen seiner eigenen Zeit stehen: Zwar sind sie den hergebrachten sprachlichen Fertigkeiten zugetan, veranschlagen aber die Einfachheit der Apostel doch noch höher. Und dieser Einfachheit gilt denn der Schluss des Gedichtes (V. 72-83), näherhin dem Jesuskind und überhaupt dem Erdenleben Christi in all seiner Niedrigkeit. Diese peroratio (ab V.57) betrifft alle drei confutationes gleichermaßen, und so scheint es sinnvoll, dass Ekkehart spätestens beim Zusammenstellen des Liber Benedictionum das Gedicht, das die erste der drei Disziplinen des Triviums betrifft, an den Schluss gestellt hat.

$9 \mathrm{Zu}$ dieser verkürzenden Betrachtungsweise Stotz 2011a, 17-22. 


\section{Zur Anordnung in der nachfolgenden Textdarbietung}

Ekkeharts Verse sind nicht besonders angenehm zu lesen, und in den drei Gedichten ist manches auch nicht gerade leicht zu verstehen. Dazu, sich mit den etwas widerborstigen Texten vertraut zu machen, dient am besten der Versuch einer neusprachlichen Übersetzung; einbezogen ist darin, so gut es sich machen ließ, auch Ekkeharts Selbstglossierung ${ }^{10}$. Der Übersetzung ist ein knapper Stellenkommentar in Form von Fußnoten beigegeben. Der Bearbeiter muss freilich bekennen, dass ihn die eine und andere Stelle nach wie vor etwas ratlos lässt. Was den lateinischen Text angeht, so kann die Ausgabe von Johannes Egli von 1909 im Großen und Ganzen noch immer ihren Dienst versehen. Allerdings gab eine Nachprüfung von Text und Glossen anhand (des Digitalisats) der Handschrift Anlass zu zahlreichen Berichtigungen ${ }^{11}$. Die Numerierung der Glossen, bei Egli auf jeder Druckseite neu beginnend, ist aus praktischen Gründen beibehalten (mit Unterstreichung, zur Unterscheidung von meinen Fußnotenzeichen). Eglis Sachanmerkungen sind zwar in manchen Dingen nicht mehr zeitgemäß, doch sind manche seiner Anregungen wertvoll. Dies gilt etwa für seine Hinweise auf zwei Notizen Ekkeharts in andern Handschriften, die gleichsam ein Echo auf die Confutatio grammatice darstellen und die hier im Anhang behandelt werden.

10 Anders als bei Egli sind die Glossen, so gut es eben ging, in den Haupttext eingegliedert. Enthält eine Glosse die Präzisierung von etwas im Text Gesagtem, steht sie in eckigen Klammern, dient sie der Vervollständigung des Satzes selber, in runden.

11 Nachstehend das Wichtigere, für alle drei Texte. (Einzelne Beobachtungen zur Genese des endgültigen Textes oder zur Lokalisierung des Lemmas bestimmter Glossen bleiben beiseite.) Nr. 40, V. 1, Gl. 1: efferri, nicht -re - 2, Gl. 3: astute, nicht acute - 5: Excidet aus -it - 8: fors am Ort (am Rand wiederholt) - 10, Gl. 15: Rethorica, nicht rheto- -13, Gl. 2: id est (.i.) vor confessio erst später, confessio zunächst vielleicht als Textvariante gedacht -14 , Gl. 4: conscius, nicht -nc- - 27: zweites nec] non - 30: si (unvollständig) radiert, darüber stehendes nos vielleicht zum Ersatz bestimmt - 31, Gl. 4: infra actionem erst später - Nr. 41, V. 1, Gl. 13: zwei verschiedene Glossen, die erste zu flatus - 3, Gl. 22: zu interpungieren wohl: Porphirius hic, quamvis - in heresi fuit erst später - 4: nach flatum kein Punkt -6 erunt, nicht erant - Gl. 2 ist nicht Glosse zu V. 6, sondern ist ein Zusatzvers (5a), wohl später als, und in Konkurrenz zu den roten Übertitelungen von V. 5 eingefügt. - 17 híc, nicht hîc (Pronomen, nicht Adverb) - 20, Gl. 19: gehört zu sophismate - 22 fit, nicht sit - 25-30, Gl. 1-6: ebenfalls alle rot - 44 am unteren Rand, erst später - Nr. 42, V. 9 (Anm.): I Cor. 2, 3 - 15: abgesehen von $R[. .$.$] ganzer Vers neu geschrieben (wie 13) - 23: Gl. 15$ gehört zu 22 (Verschiebung nicht gerechtfertigt) - Gl. 16 gehört zur 1. Vershälfte - confundat (nicht -et, Abkürzung sinnwidrig aufgelöst) - I Cor. 1, 27 - 24: archana später aus -ca- - 25: in Gl. 20 nach de pectore nur $₫$ sicher lesbar, ob dei statt domini? - 41, Gl. 12: quę dico erst später - 50, Gl. 4: simplicitati, nicht -te - 52, Gl. 10, duorum: jede Silbe trägt eine Neume - 66, Gl. 20: utrique, nicht virique - 70, Gl. 32: gehört zu amplius - quam, nicht qua. - Außerdem $e$, nicht $e$ caudata: Nr. 40, Titel: ecclesie - 23 precator (mit pre-Kürzung; Metrum!) - Nr. 42, 65, Gl. 19: ecclesie - 69, Gl. 31: loyce. 


\section{Ekkeh. IV. bened. I 40: Zurückweisung der Rhetorik im Angesicht der Kirche und der Heiligen}

12 $^{12}$ Satan, der du dich zu Großem erdreistest [Egli S. 2061 in der Kirche mit deiner Beredsamkeit groß zu tun], schweige still, denn du hast [피 im Angesicht der Heiligen] gar nichts zu bestellen. 2 Die Lehrsätze der Kirche werden dich niederdrücken und werden deine [ ${ }^{3}$ mit List ausgestattete] Zunge zähmen. 3 Die drei Sachbereiche der Rhetoren [ ${ }^{4}$ die Gerichts-, die Lob- und die Beratungsrede] weist die Betätigung des Glaubens [ ${ }^{5}$ die Dreifaltigkeit] in die Schranken. [ ${ }^{6}$ Kunstvolle Rede ist eine Betätigung, von der aber auch die Kirche Nutzen gezogen hat.] 4 Er [ ${ }^{7}$ der Glaube] hat als Rednertribünen [ $\underline{\underline{8}}$ das sind die Lesepulte] nicht Sitzbänke [ ${ }^{9}$ wie in Rom] für die Monstren $[\underline{10}$ der Laster]. 5 Dein Betrug wird von der Gerichtssache ausgeschlossen und vollführt das kühn Beabsichtigte nicht. [ 11 Ein Redner, der nicht nach Art der Rhetoren verfährt, wird des Platzes verwiesen. Daher heißt es in der Vita Vergils: Einmal führte er einen Prozess, und weil er ihn nicht angemessen führte, obwohl er anderweitig höchst beredt war, misslang der Prozess ${ }^{13}$.] 6 Nachdem der Schöpfer am Kreuz deine Macht gebrochen hat, wirst du nicht mehr Sachwalter sein, 7 und mit deinem Beifall im Theater ist es für immer vorbei $\left[{ }^{12} \mathrm{zu}\right.$ Ende].

8 Für die Unseren ist die Gerichtssache $\left[\frac{13}{3}\right.$ Die Gerichtssache ist der Gegenstand, um dessentwillen der Ankläger und der Verteidiger vor Gericht streiten.], falls sie etwa einmal auf der Rednertribüne zu betreiben ist, 9 etwas, was den Gerichtsstand zugunsten der Gefallenen anderswohin überträgt, ein Verfahren, das begnadigt. $[\underline{14}$ Übertragener Gerichtsstand bedeutet etwa, dass, wenn in Konstanz schlecht geurteilt worden ist, nach Mainz appelliert wird ${ }^{14}$. Paulus sagte (Act. 25, 11): Ich berufe mich auf den Kaiser.] 10 Anschuldigungen, die der Prätor geschrieben hat, schreibt der Zensor um [ 15 Der Prätor schreibt, dass jemand der Tempelschändung schuldig sei, der Zensor dagegen: des Diebstahls. Was der Prätor für sich aufgeschrieben hat, das meint in der Redekunst das, was verdeckt angedeutet wird.] ${ }^{15}, \mathbf{1 1}$ indem er die

12 Beischrift am Rande: Tagespensum für den Lehrer.

13 Don. vita Verg. 15f.: Egit et causam apud iudices unam omnino nec amplius quam semel; nam et in sermone tardissimum ac paene indocto similem fuisse Melissus tradidit; vgl. Virgilian tradition 2008, 183, 191.

14 Gemeint ist das bischöfliche Gericht in Konstanz, von dem man einen Fall an das erzbischöfliche in Mainz weiterziehen konnte.

15 Ekkehart scheint die beiden römischen Amtsbezeichnungen hier ganz so zu verwenden, als sei der praetor der (reguläre) Ankläger, der censor der (reguläre) Richter. censor war im mittelalterlichen Latein in der allgemeinen Bedeutung von ,Richter‘ allerdings recht geläufig; vgl. z.B. MLW 2, 451, 52-64. Auf welchem Wege aber für Ekkehart der Prätor, der die Anklage ja vielmehr entgegenzunehmen hatte, selber zum Ankläger geworden ist, wäre noch zu ermitteln. Zu seinen Vorstellun- 
Gattung oder die Absicht neu fasst $\left[\frac{16}{6}\right.$ nämlich die Art und Bestimmung ${ }^{16}$ des eingeklagten Tatbestandes], auch die Bezeichnung ändert [17 so dass er die Tempelschändung Diebstahl nennt], 12 ausforscht, worum es sich handle, mitunter auch das Eine durch das Andere vertauscht [ $[\underline{18}$ was es sei, was der Prätor für sich aufgeschrieben hat, damit er es bestrafe.]

13 Hier ( ${ }^{\text {gli }}{ }^{\text {S. }} 2071$ ist) der gütige Gott selber der Zensor, das Eingeständnis [를 das heißt die Beichte] ( 3 ist) der Prätor. 14 Der Prätor gibt ein Zeichen, der Zensor ein des Kreuzes und des Lobes würdiges. [ ${ }^{4}$ Bei den Gläubigen streitet der Schuldbewusste ${ }^{17}$ es entweder ab oder bekennt es, Christus als der Zensor bestraft oder lässt die Schuld nach.] 15 Der Zensor [ ${ }^{6}$ Christus] verwandelt [ ${ }^{5}$ lässt nach] die Sünden, die von dem [ ${ }^{7}$ zugebenden] Prätor gerügt [ ${ }^{8}$ bekannt und beweint] worden $\operatorname{sind}^{18} .16$ Oder $\left({ }^{9}\right.$ wenn) Satan selber der Prätor [ $\left[\underline{10}\right.$ der Rügende] ist, dann wandelt sie der Zensor [ ${ }^{11}$ Christus] um. 17 Wenn es zu Reuetränen kommt, schreibt er [를 der Zensor] es sogleich um, und der Verwandelte [ $\underline{13}$ der Buße Tuende] geht [ $\underline{14}$ frei von seiner Schuld] von dannen, 18 und dem Beschuldigten droht [ $\underline{15}$ nachher] kein Schrecken [ $\underline{16}$ weder von Seiten des Prätors noch des Zensors], wenn der Fehler bereut wird ${ }^{19}$. [17 Dieser Sinn von Umwandlung lässt sich in den rhetorischen Schriften schwerlich fassen, denn Cicero hat über Dinge geschrieben, die seinen Lesern geläufig waren, wobei er das bürgerliche Recht mehr nur berührt als erklärt hat ${ }^{20}$.]

19 Auch wissen wir wohl, dass es nach den [ํㅡㄹ rhetorischen] Darlegungen ${ }^{21}[\underline{19}$ für den

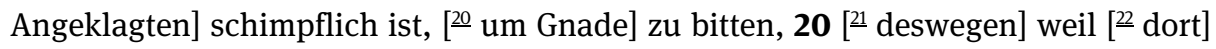
der Zensor sich in Bitterkeit selten durch Bitten erweichen lässt. [른 In Gerichtsfällen galt die Bitte um Gnade als ganz und gar ungehörig.]

gen über die Rollenverteilung im römischen Gerichtswesen siehe auch die (von Egli XLV angeführte) Scholie aus Handschrift 168, S. 129.

16 diffinio, -onis fem. ist eine Eigenheit der Sprache Ekkeharts (vgl. MLW 3, 616, 16-20).

$17 \mathrm{Zu}$ dieser Bedeutung von conscius MLW 2, 1499, 56-60.

18 transferre crimen, translatio criminis bezeichnen im römischen Strafrecht die Überwälzung der Schuld für eine Straftat durch den Angeklagten auf jemand anders; dazu Rhet. Her. 1, 15, 25; Gell. 6, 3, 15; auch Cic. invent. 1, 11, 15 (Causa transferetur [...]) usw. Ekkehart verwendet transferre hier jedoch im Sinne von ,vergeben, nachlassen'. Allenfalls steht als vermittelnder Gedanke im Hintergrund, dass die Sünden der Menschen auf Christus überwälzt worden seien (vgl. etwa Is. 53, 5; I Petr. 2, 24 u. ä.). - Ekkehart selber weist in Glosse 17 darauf hin, dass dieser Wortgebrauch in den rhetorischen Lehrtexten kaum vorkomme.

19 si pęnitet error $\approx$ si p. erravisse.

$20 \mathrm{Zu}$ dieser Glosse (am Seitenfuß) bringt Egli Materialien bei.

$21 \mathrm{Zu}$ den Eigentümlichkeiten in Ekkeharts IV. Dichtungen gehört der Gebrauch von femininem acta im Sinne von ,Rede, Erzählung'; vgl. MLW 1, 402, 43-50. Zu einer Übersetzung in diesem Sinne nötigt hier aber eigentlich nur die Glosse rhetoricis. Sonst läge es nahe, in actis im Sinne von ,in (Gerichts-)Verhandlungen' aufzufassen. - Zur deprecatio (als einer der beiden Formen der concessio): Cic. invent. 2, 34, 104; Rhet. Her. 1, 14, 24. 
21 Diese Gepflogenheit [ ${ }^{24}$ nämlich, nicht zu bitten] ist in unseren [ ${ }^{25}$ der Gläubigen] Geschäften [탐 Verfahren] gänzlich in Abgang gekommen, 22 und die beste Lage ist [글 bei uns], wenn der Schuldige seine Schuld [ ${ }^{28} \mathrm{im}$ Gebet] $\mathrm{zu}$ beweinen bereit ist.


Angelegenheiten betreibt und der nämliche als Bittsteller [ $\underline{33}$ für die Schuldigen], 24 und auch Paulus als unser Fürsprecher [ $[4$ als Redner] mit seinem Gebet glückhaft ( 35 unsere Sache) betreibt; 25 zudem sollen auch alle Heiligen voller Erbarmen [ 6 für die Schuldigen] einstehen.

26 Auch fürchtet Paulus, wenn er vor Gericht plädiert, keine Männer wie Tertullus [ ${ }^{37}$ Das ist der Apostelgeschichte (Act. 24, 1-9/10-21) entnommen], 27 noch ( $\stackrel{38}{\text { fürch- }}$ ten) wir das Gewicht Frontos ${ }^{22}$, auch nicht die Durchschlagskraft Ciceros.

28 Wenn hier die Bitte eines einzigen Benetzten [ $\frac{39}{}$ eines in der Kirche Getauften], eines Heiligen am Werke ist, 29 wird Christus [ $\underline{41}$ unser Zensor], durch ( $\underline{40}$ seine) unterwürfige Bitte alsbald erweicht, gnädig gestimmt werden.

30 Wenn (Egli S. $208{ }^{1}$ wir $^{23}$ ) im Gebet stehen und, indem wir (를 das Gehörige erbitten, 31 weswegen unser Handeln mit dem Fürsten [ $\underline{3}$ des höchsten Fürsprechers] den Namen ,Kanon“ [ ${ }^{4}$ das Te igitur innerhalb des Hochgebets $\left.{ }^{24}\right]$ innehat, 32 dann wird Quintilian [ $\underline{6}$ der sagt, in einer Gerichtssache sei eine Bitte schimpflich $^{25}$ ] ein nichtiger Lehrer der Rhetorik ${ }^{26}\left[\frac{5}{5}\right.$ der Beredsamkeit] sein. 33 ( ${ }^{7}$ Und wenn auch) die Rhetorik selber erdröhnt [ $\underline{8}$ wie man so sagt] und ihre Blitze [ ${ }^{9}$ derentwegen dann von Ciceros Donnerschlägen die Rede ist] niedergehen lässt $[\underline{10}$ zurücklässt $]^{27}$, 34 so mögen doch jetzt die Rhetoren $\left[11\right.$ die Meister ${ }^{28}$ dieser alten Kunst] weichen, zurückgelassen als überwunden und als träge.

22 Die Briefe Frontos (2. Jh. n. Chr.) waren im Mittelalter unbekannt. Wenn Ekkehart hier - und in bened. prol. 2, 58: Frontonis gravitas - Fronto als gewichtigen Redner anführt, so nur auf Grund spätantiker Erwähnungen. An Ort und Stelle dürfte dies auf Mart. Cap. 5, 432 zurückgehen, wo Fronto nebst andern berühmten Rednern im Gefolge der Rhetorica erscheint.

23 nos sollte vielleicht si ersetzen (siehe Anm. 11), somit wäre aus dem (doppelten) BedingungsVordersatz ein Aufforderungssatz geworden.

24 Mit der Konsekrationsbitte Te igitur, clementissime pater [...] (Sacr. Greg. Nr. 5) wird der Canon missae, das eucharistische Hochgebet, eröffnet. - Ekkeharts späterer Zusatz (vgl. Anm. 11) infra actionem (als Rubrik sonst dem Gebet Communicantes [...] zugeordnet) bezieht sich gewiss auf die (Opfer-)Messe als ganze. Zu actio für canon: Walahfr. exord. 23, MGH Capit. 2, S. 502, 10: canon [...] actio nominatur.

25 Quint. inst. 6, 1, 24; vgl. V. 19.

26 Das - auf der ersten Silbe falsch gemessene, vielleicht durch rhesis angeregte - rhetoresis dürfte Ekkeharts lexikalischem Eigengut angehören.

27 Zum hyperbolischen Gebrauch von fulmen und tonare im Zusammenhang mit der Beredsamkeit Egli zur Stelle. 


\section{Ekkeh. IV. bened. I 41: Ebenso Zurückweisung der Dialektik}

1 Das unbedingt Gültige ${ }^{29}$ [Egli S. $208 \underline{12}$ den logischen Scharfsinn] führt hier [ ${ }^{13}$ in der Kirche der Geist ${ }^{30}$ ] der heilige Hauch ins Feld [ ${ }^{14}$ Lies bei Martianus Capella nach ${ }^{31}$.], 2 dieser [ $\underline{15}$ der Geist] durchquert mit seinem Wirken die fünf $[\underline{16}$ Gattung, Art, Begleitumstand, Differenz, Individuum] ,Eisagogai ‘ $\left[\frac{17}{}\right.$ Einführungen] besser ${ }^{32} ; 3$ diese

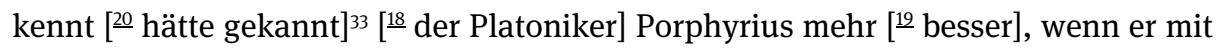
ihm als Führer [ $\underline{21}^{2}$ mit dem Heiligen Geist als Lehrer] danach fragt ${ }^{34}$. [ ${ }^{22}$ Dieser Porphyrius war, obwohl getauft, ein erbitterter Feind des Glaubens, und niemand setzte durch seinen Scharfsinn den Gläubigen jemals härter zu, in einem Irrglauben befangen ${ }^{35}$.]

4 Im Vater, durch den Sohn und den Geist, mit dessen Kraft verbunden, 5 bestehen alle Dinge unter drei Arten in Bezug auf die Subjekte ${ }^{36}$ [ ${ }^{\text {Egli S. }} 20911$ das Subjekt, vom

28 artigiasus ,Künstler, nach ars, artis; vgl. MLW 1, 1001, 23-25, wo an it. artigiano erinnert wird. (Aber -as-bleibt auffällig.)

29 axioma wird auch im mittelalterlichen Latein für einen grundlegenden Satz, der nicht bewiesen werden muss, gebraucht; der Dichter rückt hier, wohl zwecks plakativer Gegenüberstellung, von diesem terminologischen Gebrauch ein klein wenig ab (vgl. MLW 1, 1295, 55f.).

30 Eigentlich zwei verschiedene Glossen, siehe Anm. 11.

31 Ekkeharts Hinweis auf Mart. Cap. steht zwar am Schluss des Satzes, bezieht sich jedoch schon auf axioma. Gemeint ist 4, 327, V. 3f., betreffend den Auftritt der Dialectica vor der Götterversammlung: In coetum superum veniens primordia fandi/advehit et scholicum praestruit axioma (,[...] sie hält die unumstößliche Lehre in Bereitschaft“ [o. ä.]). Hier ist nun der Heilige Geist der Handelnde.

32 Hier geht es um die fünf Prädikabilien, von Ekkehart in Anlehnung an die Einleitungsschrift des Porphyrios, in einer freilich recht auffälligen Verdinglichung, ysagogae genannt. Isidor (orig. 2, 25, 1) verwendet isagogae im Plural. Nach der Erklärung des Begriffs (,introductio') gelangt er recht bald zur Erörterung von genus, species usw. Vielleicht bewegt sich Ekkehart in dessen Fahrwasser. - Für die Stelle insgesamt verweist Egli auf Mart. Cap. 4, 344ff. Allerdings erscheinen die species dort unter der (Haupt-)Bezeichnung formae, die differentia geht dem accidens voraus, und was Ekkehart als individuum bezeichnet, heißt dort proprium. Ob Ekkehart gerade auch hier Mart. Cap. folgt, muss wohl offen bleiben.

33 Faktisch nur Wechsel von der (wohl nur äußerlich, durch den Reim) motivierten Indikativform zu der (hier gegebenen) Form des irrealen Konjunktivs.

$34 \mathrm{Zu}$ Porphyrios und seiner von Boethius übersetzten und kommentierten ,Eisagoge، (Einführung in die Kategorien des Aristoteles) sowie zu seiner Streitschrift ,Gegen die Christen` Chase/Harmon 2001.

35 in heresi fuit ist Nachtrag (siehe Anm. 11).

36 Dies geht auf Mart. Cap. 4, 361 zurück, wo es heißt: Omne quicquid dicimus, aut subiectum est aut de subiecto aut in subiecto aut de subiecto et in subiecto. Subiectum est prima substantia [...] - Zu diesem Thema vgl. auch Ekkeh. IV. bened. I 57, 22. 
Subjekt, im Subjekt] - 5a $\mathbf{a}^{37}$ das Subjekt, vom Subjekt, wie auch im Subjekt selber 6 ganz nah beieinander, und von all dem Erschaffenen ist noch nichts vorhanden.

$7^{38}$ Nach den zehn Worten der Logik [ 3 den zehn Kategorien], die durch ihre Wirkkraft hervorragend [ ${ }^{4}$ edel] sind, 8 erlässt die neue Ordnung zehn [ $\left[\frac{5}{1 e}\right.$ Richtschnur des Evangeliums] (ํㅡㄴ Worte) nach dem Glauben, voll des Geistes 9 durch Männer wie Matthäus, Lukas, Markus und den erhabenen Johannes, 10 ungeachtet der Zehnerreihe $\left[{ }^{7}\right.$ in den zehn Worten des Gesetzes] der alten Gesetzestafeln.

$\mathbf{1 1}^{39}$ Die trügerische Kraft von in die Quere gehenden Aussagen zurücklassend, 12 ist unsere einfache Feststellung [ $\underline{8}$ die auch argumentum heißt], wenn als Aussage vorgebracht, kurz:

$\mathbf{1 3}^{40}$ [ 9 So:] Der nach Personen Dreifaltige ist der eine Gott, ohne jede Aufteilung. [ํㅡㄹ Das nennt man aussagende Form.]

14 Auch wird durch Scheidung in zwei eine hypothetische Aussage ${ }^{41}$ bewerkstelligt:

$15^{42}$ [11 So:] Wenn er nach Personen dreifaltig ist, doch seiner Göttlichkeit nach ein Einziger [ ${ }^{12}$ Das nennt man bedingungsweise annehmende Form.], $16^{43}$ zeichnet sich unsere Syllogistik ${ }^{44}$ [ $\underline{13}$ das vernünftige Schließen des Glaubens] durch siebenfache

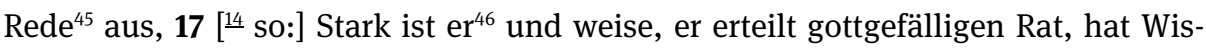

37 Diese von Egli als Glosse zu V. 6 missverstandene Zeile ist ein Zusatzvers, augenscheinlich erst nach den (roten) Übertitelungen von V. 5 eingefügt, in Konkurrenz zu ihnen (vgl. Anm. 11).

$38 \mathrm{Zu}$ den Versen 7-10 als Randtitel: Kategorien. Zu erinnern ist an die Übersetzung der Kategorienschrift des Aristoteles durch Boethius (Boeth. categ.) und deren Bearbeitung durch Ekkeharts Lehrer (St. Galler Handschrift 818, 11. Jh.).

$39 \mathrm{Zu}$ den Versen 11f. als Randtitel: Perierm/enias〉, die mittelalterliche Form von Perì hermeneías, ,De interpretatione', als Titel der zweiten Schrift des aristotelischen Organons, der Sache nach: ,Lehre vom Satz'. - Den Hintergrund zu V. 11f. bildet Mart. Cap. (4, 390), wo proloquium so definiert wird: Quod [...] fuerit ex nominativo casu nominis et tertia verbi persona coniunctum, proloquium dicitur, ita ut iam necessario aut verum sit aut falsum aut dubium (folgen Beispiele). Wohl hauptsächlich mit Blick auf die letzten beiden Möglichkeiten spricht Ekkehart von der lubrica vis der proloquia. proloquium ,Aussage' dient bei Mart. Cap. (und manchenorts) zur Wiedergabe von axioma; ThLL 10, 2, 1835, 6-29.

$40 \mathrm{Zu}$ Vers 13 als Randtitel: aussagender (sc. Syllogismus); vgl. Mart. Cap. 4, 408, wo es um den kategorischen Syllogismus geht.

$41 \mathrm{Zu}$ dieser Anwendung von condictum: MLW 2, 1252, 12-16.

$42 \mathrm{Zu}$ Vers 15 als Randtitel: konditionaler (sc. Syllogismus); Mart. Cap. 4, 414.

$43 \mathrm{Zu}$ den Versen 16-18 als Randtitel: ebenso.

44 syllogies ist wohl eine ad hoc-Wortbildung Ekkeharts, der Versbequemlichkeit zuliebe.

$45 \mathrm{Zu}$ femininem acta vgl. Anm. 21. 
sen, hat Furcht ${ }^{47}$, er schenkt Gehör. 18 Nichts ist größer als sie [ $[\underline{15}$ die Rede des Glaubens], kraft ihrer Vernunftgemäßheit kämpft sie sich durch alles durch.

19 Aber ( $\underline{16}$ aus) drei Teilen besteht das alte ( $\frac{17}{7}$ vernünftige Schließen), welches vielfältig ( $\frac{18}{}$ ist) in fünf Dingen, $\mathbf{2 0}^{48}$ die bisweilen erfunden und durch schlüpfrigen sophistischen Trug $\left[{ }^{19}\right.$ in vorgeblicher Weisheit] gefärbt [ํㅡㄹ abgewandelt] sind.

21 Hier aber gibt es keine bemalte Tafel [ ${ }^{21}$ Lies bei Martianus Capella ${ }^{49}$ nach.], hier richtet der Haken, richtet die Schlange nichts aus. 22 Nachdem die Vordersätze angenommen sind, wird ${ }^{50}$ die Schlussfolgerung [르 die drei Teile eines Syllogismus] für die Unseren gültig [ ${ }^{23}$ passend]. $\mathbf{2 3}^{51}$ Wenn die Vordersätze angenommen sind, ( 24 ergibt sich) den Unseren die Schlussfolgerung. 24 Mag durch die Kunst ein zweizeiliges System ${ }^{52}$ gegeben worden sein, so weiß der Heilige Geist doch mehr als das.

$25^{53}$ [Egli S. 21011 Obersatz:] Eine Frau, die geboren hat, die hat ja freilich zuvor Umgang mit einem Mann gehabt, 26 [를 Annahmesatz:] aber Maria gebar ein Kind und hatte doch niemals Umgang mit einem Mann. 27 [ํㅜㄴ Schlussfolgerung:] Eine Frau blieb Jungfrau und gebar, ohne Umgang mit einem Mann gehabt zu haben.

$\mathbf{2 8}^{54}$ Die kreisförmige Bewegung ${ }^{55}$ des Glaubens findet ihr Ende dort, von wo sie ausgegangen ist [ ${ }^{4}$ nach sophistischer Weise, jedoch wahr]: 29 [ ${ }^{5}$ Ausgangspunkt:]

46 híc, nicht hîc (siehe Anm. 11). - Siebengliedrig würde diese Aussage, wenn man sich an der Stelle des Adverbs piě das Adjektiv pius dächte.

47 Bei timet mag etwa an die Furcht Jesu im Garten Gethsemane gedacht sein.

$48 \mathrm{Zu}$ Vers 20 als Randtitel: ebenso.

49 Angespielt ist auf Mart. Cap. 4, 328, mit dem Auftritt der Dialectica vor der Götterversammlung. In der linken Hand hält sie eine vielfach gewundene Schlange, während in dextra formulae quaedam florentibus discolora venustate ceris sollerter effigiatae latentis hami nexu interius tenebantur. Gedacht ist an Syllogismusfiguren (figurae), die auf Wachstäfelchen (cerae, Plural) sorgfältig aufgezeichnet sind und mit einem verbindenden Haken (hami nexu) zusammengehalten werden; vielleicht darf man dabei an die Klammern denken, welche Diptycha/Triptycha verbinden. Ekkehart spricht von einer einzigen Tafel. Entsprechendes finden wir auch in der Buchmalerei, so sehr schön in Paris, BnF lat. 7900 A Bl. 132"; vgl. Remigius Autissiodorensis 1965, Tafel vor S. 9. Da es dann also nichts zusammenzuhalten gab, wird die Vorstellung des hamus freigesetzt: er wird (im Sinne etwa eines Angel- oder Enterhakens), parallel zu „Schlange“, für ein Werkzeug genommen, mit dem der Gegner gepackt werden kann (so gerade auch auf der genannten Abbildung).

50 fit, nicht sit (siehe Anm. 11).

51 Dieser (zusammen mit dem folgenden) am unteren Rand der Seite eingetragene Vers ist inhaltlich eine Dublette zu Vers 22.

52 Gedacht ist offenbar an die beiden Prämissen, Ober- und Untersatz, eines Syllogismus. Diese Anwendung von distichon scheint ungebräuchlich zu sein.

$53 \mathrm{Zu}$ den Versen 25-27 als Randtitel: Syllogismus.

$54 \mathrm{Zu}$ den Versen 28-30 als Randtitel: ebenso. 
Was der Vater, das ist der Sohn, und beiden gleich ist auch der Geisthauch. 30 [트gebnis:] Was der heilige Geisthauch, das ist der Sohn und auch der heilige Vater.

$31^{56}$ So gibt denn der Glaube den Satz vor $^{57}$ und in einem auch die Argumente,

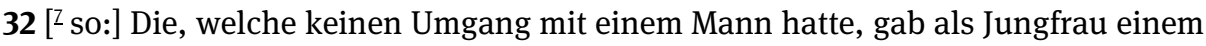
Kind das Leben. 33 So verliert die Logik ihre Kraft dadurch, dass Maria gebar: 34 sie, die doch die höchste Gewalt besessen hatte (mit dem Satz): wenn sie gebiert [ํㅛ für: geboren hat], hat sie vorher Umgang mit einem Mann gehabt.

$35^{58}$ Die Weisheit ist [ ${ }^{9}$ bei den Logikern] eine doppelte: die eine schweigt, doch die andere redet, 36 die eine [ ${ }^{10}$ die peripatetische] zieht auf den Straßen umher, die andere [ ${ }^{11}$ die stoische] sitzt in gemauerten Wandelhallen. 37 Die eine [를 trachtet danach, $\mathrm{zu}$ reden und $\mathrm{zu}$ hören, die andere [ $\frac{13}{}$ die peripatetische] macht sich auf, um zu sehen.

38 Das erhabene Volk der Kirche kennt in noch passenderer Weise eine zweifache ( 14 Weisheit), 39 indem es sich hier der Betrachtung hingibt, hier dem Tun dessen, was sich ziemt; $\mathbf{4 0}^{59}$ dem einen steht Martha vor, dem andern Maria.

$41^{60}$ So freue sich denn ( $\left.15 \mathrm{im}\right)$ Himmel die ewig lebende Bürgerschaft, 42 welche das entkräftet, was zuvor seiner Gestalt nach kräftig war, 43 ( $\frac{16}{6}$ welche) Menschen wie Platon und den strengen Cato $^{61}$ zuschanden macht. 44 Jetzt sollen die Logiker weichen und sollen keinen durch ihre Sophistik verletzen ${ }^{62}$.

$55 \mathrm{Zu}$ dieser Anwendung von circulus in Anlehnung an den terminologischen Gebrauch im Sinne von ,Zirkelschluss': MLW 2, 600, 56-58.

$56 \mathrm{Zu}$ den Versen 31-34 als Randtitel: ebenso.

57 membrum bedeutet in der Rhetorik etwa ,Satzglied“ und wird oft als Terminus für ,Kolon` angewandt (vgl. ThLL 8, 644, 50-645, 18), wird dann aber auch im Bereich der Logik, etwa im Sinne von ,Satz, Glied eines Syllogismus‘ gebraucht; vgl. NGML M/N 351, 26-31; DBrit 1758b (membrum 4c).

58 Zu den Versen 35-37 als Randtitel: ebenso. - Egli bemerkt, dass Ekkehart den mehr empirischen Charakter der peripatetischen Schule hervorhebe, während die Stoiker auf spekulativer Grundlage die Erforschung der Wahrheit sich zum Ziele setzten. Doch geht er wohl eher vom Wortsinn der Benennungen der beiden Schulen aus; sein Ziel, die Dichotomie der beiden christlichen Daseinsweisen (V. 38-40) damit zu verknüpfen, scheint mir bereits hier angebahnt.

59 Der ganze Vers ist nachträglich an die Stelle eines andern gesetzt worden.

$60 \mathrm{Zu}$ den Versen 41-44 als Randtitel: ebenso.

$61 \mathrm{Vgl}$. auch Ekkeh. IV. bened. prol. 2, 47: rigidum [...] senem [...] Catonem, wo es um die moralische Spruchsammlung in Hexameterpaaren geht, die unter dem Namen des älteren Cato (Cato Censorius, 234-149 v. Chr.) umläuft (,Disticha Catonis', Ps. Cato. dist.). Dass auch an unserer Stelle hierauf angespielt sei (so Egli), ist wohl unnötig anzunehmen, angesichts von Catos sprichwörtlicher Strenge. 62 sophisticę ist wohl als Adverb zu nehmen; die metrisch bedingte Verkürzung der Schlusssilbe von Adverbien auf $-\bar{e}$ ist nicht selten (vgl. oben V. 17), ebenso wenig die Schreibung von $e$ anstelle von $e$. 


\section{Ekkeh. IV. bened. I 42: Zurückweisung der Grammatik}

1 Die Grammatik soll die Messer schonen und sich die freie Zeit mit Peitschen vertreiben [ ${ }^{\text {Egli S. } 2111}$ Lies bei Martianus Capella nach ${ }^{63}$.] 2 Dem Glauben ist erlaubt, seine Worte ohne Fesseln [를 der Regeln] und ohne Gesetz auszusprechen ${ }^{64}: 3$ ihm [ ${ }^{4}$ nämlich: dem Glauben], dem die Stimme der Fischer [ ${ }^{3}$ nicht die der Städter] das Himmelreich aufschließt. 4 Der Fischer Petrus lehrt diesen ( 5 Glauben), kein Liebhaber der [ ${ }^{6}$ Sprach-] Kunst. 5 Er erweist, dass die Gesetze der Grammatik [ ${ }^{7}$ nämlich ihre Regeln] wenig fest sind, $\mathbf{6}$ und er zeigt, dass der Glaube dem Gehalt der Sprachkunst wenig zugetan ist ${ }^{65}$.

7 Paulus lässt in Niedrigkeit seine Stimme zu seinen ( $\underline{8}$ des Glaubens) Gunsten in kurzen ( ${ }^{2}$ Briefen ${ }^{66}$ ) erschallen und ist vor sich selber gering [ ${ }^{10}$ ohne Sprachkunst], 8 welcher, hohe und hochfahrende Worte [ 11 der Sprachkunst und Beredsamkeit] meidend, 9 in Einfalt [ $[\underline{2}$ ohne diese beiden] Christus predigt, und zwar ihn als den gekreuzigten [ ${ }^{13}$ was er freilich eine Torheit nennt $\left.{ }^{67}\right] .10$ Untersuche ${ }^{68} \mathrm{du}$, der du das [14 nämlich untersuchen] kannst, viele Stellen in seinen Schriften, 11 dann erkennst

63 Gedacht ist an Mart. Cap. 3, 223-229, an den Auftritt der Grammatica vor der Götterversammlung. Sie trägt ein mit Elfenbein besetztes Kästchen, dem sie ihre Mittel zur Heilung von Sprachfehlern entnimmt: ein scalprum [...], quo dicebat circumcidi infantibus vitia posse linguarum, verschiedene Medikamente sowie eine Feile. Wenn Ekkehart scalpra im Plural verwendet, denkt er vielleicht (auch) an Federmesser. Und wenn ihr hier zum Zeitvertreib mit flagra geraten wird (dieses Wort nicht bei Mart. Cap.), könnte man allenfalls an Peitschen denken, mit denen Kinder ihre Kreisel antreiben. Vgl. hierzu das epische Bild in Verg. Aen. 7, 378-383, ferner Pers. 3, 51 (im Übrigen: Hurschmann 1999). Jedenfalls scheint die Rute, das im Mittelalter sonst geläufige Attribut der Grammatica, hier gerade nicht im Spiele zu sein. Denn diese soll ja ,dienstfrei‘ sein.

64 Egli stellt diese programmatische Leugnung der Autorität der grammatischen Instanzen über das Wort Gottes in Zusammenhang mit dem Auflösungsprozess hochsprachlicher Sprachkompetenz in der Völkerwanderungszeit und hält der Kirche beigelegte Impulse praktischer Art gar für eine ihrer Ursachen. Wir sehen das heute etwas anders.

65 Petrus wird hier - und nachher, in V. 16-21, zusammen mit seinem Bruder Andreas - nicht etwa als Verfasser der ihm zugeschriebenen beiden Briefe genannt, sondern als der einfache Fischer, der er seiner Herkunft nach war. Zu der Diskurstradition des sermo piscatorius oben Kap. 1.2.

66 Damit ist brevibus adjektivisch und epistolis als dessen substantivische Ergänzung aufgefasst; weniger wahrscheinlich ist substantivisches breve (zu deutschem ,Brief“ entlehnt), wonach die Glosse ein Synonym enthielte. (In diesem Sinne wird die Stelle in MLW 1, 1576, 71, aufgefasst.)

67 Vgl. I Cor. 1, 23: Nos autem praedicamus Christum crucifixum, Iudaeis quidem scandalum, gentibus autem stultitiam.

$68 \mathrm{Zu}$ construere als grammatischem Terminus: ThLL 4, 548, 6-12; MLW 2, 1647, 19-31, usf. Hier nun ist darunter die nachvollziehende grammatische Analyse eines bereits gegebenen Textes verstanden; vgl. das (später) häufige construe sic: [...]. 
du, dass ( ${ }^{15}$ ihr $\left.{ }^{69}\right)$ jeweiliger Sinn den [ ${ }^{16}$ grammatischen] Bau unbehelligt hinter sich lässt [ ${ }^{17}$ nicht einhält], 12 und du wirst sagen, dass der Mann in keinerlei grammatischen Lehren bewandert sei. $\mathbf{1 3}^{70}$ Das erweist auch der hervorragende erste Leseabschnitt des Comes $^{71} .14$ Und er ist mehr vom Himmel gelehrt als zu den Füßen Gamaliels $^{72}, \mathbf{1 5}^{73}$ er lässt aus seinem Herzen das gute Wort hervordringen ${ }^{74}$, dies ohne Donats Gesetz.

16 Bethsaida [Egli S. 2121 die Stadt von Andreas und Petrus] kennt diese Gepflogenheit nicht, noch die Strenge [ $\underline{2}$ die Regelhaftigkeit] in der Setzung der Wörter, 17 ( $\underline{3}$ Bethsaida), das Haus von Fischern ${ }^{75}$, deren Stimme auf dem ganzen Erdkreis erscholl [ ${ }^{4}$ In die ganze Welt ist (ihre) Stimme ausgegangen (vgl. Psalm 18/19, 5; Rom. 10, 18).]. 18 Sagst du etwas auf städtische Weise [ $\frac{5}{5}$ wenn du gemäß der Sprachrichtigkeit sprichst], dann hält diese Stadt [ ${ }^{6}$ Bethsaida] es für nutzlos, $\mathbf{1 9}^{76}$ wenn das überhaupt eine Stadt ( $\underline{7}$ gewesen wäre), was vielmehr, gemäß ihrer Rede [ ${ }^{8}$ Sprechweise], ein ländlicher Weiler ( ${ }^{2}$ war). 20 Petrus, größer [ $\underline{10}$ kraft der Autorität seines Glaubens] als der korrekt sprechende ${ }^{77}\left(\underline{12}\right.$ Grammatiker) Aristarchus ${ }^{78}$, stammt von hier $\left[\frac{11}{1}\right.$ aus

69 Worauf das feminine earum hier, in der Nachbarschaft von lauter pluralischen Neutra, zu beziehen ist, wird nicht klar; allenfalls auf epistolae (vgl. oben Glosse 9).

70 Dieser Vers ist in der Handschrift später eingeschoben worden.

71 Der Comes oder Liber comitis enthält, nach der Ordnung des Kirchenjahres, die Lesungen der Messe entweder insgesamt oder aber nur die ,Episteln' (Perikopen aus den Apostelbriefen und den Propheten). Vgl. Vogel 1966, 286(f.) mit Anm. 137. Die erste Perikope ist Rom. 1, 1-6, wo Paulus über seine Berufung zum Apostelamt durch Christus Zeugnis ablegt. Aber worin genau Ekkehart hier eine Aussage über dessen mangelnde formale Bildung erkennen will, wird nicht eigentlich klar. Auch ein Blick in den Kommentar zum Liber comitis, den Smaragdus von St-Mihiel ( $†$ um 825) verfasste, hilft nicht eigentlich weiter. Vgl. Rädle 1974; zu unserer Perikope (gedruckt: PL 102, Sp. $15^{\mathrm{B}}-18^{\mathrm{B}}$ ) S. 146. 220f. Smaragds Text ist überliefert in den St. Galler Handschriften 424 (Mitte 9. Jh., hier S. 57) und 435 (um 810, hier S. 2-5); der Lektionartext selber etwa noch in der St. Galler Handschrift 374 (11. Jh., hier S. 211f.).

72 Vgl. Act. 22, 3: Ego sum [...] nutritus [...] secus pedes Gamalihel, eruditus iuxta veritatem paternae legis.

73 Der Vers wurde nachträglich an die Stelle eines andern gesetzt.

74 Vgl. Psalm 44/45, 2: Eructavit cor meum verbum bonum [...].

75 Bethsaida bedeutet ,Haus/Ort der Fischerei‘; vgl. Haag 2003, 76; gewiss kannte Ekkehart eine derartige Wiedergabe. Bethsaida steht bei ihm geradezu emblematisch für „einfache christliche Sprechweise"; das wird bekräftigt durch zwei Einträge in St. Galler Handschriften: 159, S. 13 (vgl. Anhang I): Neque enim piscatores illi a Bethsaida [...] urbanius docuerant ad literam, quam domi didicerant. Und ferner Handschrift 279, S. 424 (vgl. Anhang II): simplicitatem locutionis de Bethsaida piscatorum malle quam urbanitatis leporem.

76 Anders als Egli nehme ich nach, nicht vor Vers 19 starke Interpunktion an. Der Satz scheint mir eine Berichtigung des vorher (um des Wortspiels willen) eingeführten Begriffs urbs zu sein.

$77 \mathrm{Zu}$ der dichterischen Wortschöpfung rectiloquus: Alcuin. carm. 42, 6; Dungal carm. 20, 1, 2.

78 Gemeint ist der höchst einflussreiche alexandrinische Philologe und Grammatiker Aristarchos von Samothrake (ca. 216-ca. 144 v. Chr.). Erwähnungen bei Cicero, Horaz und vielen andern zeugen 
Bethsaida]; 21 Andreas ( $\underline{13}$ wurde daraufhin) angeworben und wurde durch das schlichte [ $\underline{14}$ törichte] Kreuz zu einem schlichten Menschen ${ }^{79}$.

22 Denn sie, die Paulus [ $\frac{15}{15}$ Das Schwache in der Welt hat Gott erwählt ...] sich unterstand, Torheit zu nennen, 23 die hat Gott sich erwählt $[\underline{16}$... um das Starke zuschanden zu machen ${ }^{80}$.], der mit seiner Kraft das Starke gebrochen hat.

24 Die Geheimnisse des Herzens ${ }^{81}$ ( 17 des Herrn), die heilsamen Lehren der Gottheit, 25 dieses ( $\underline{20}$ von der Brust des Herrn) Getrunkene kredenzt [ $[\underline{19}$ der Welt] der ( $\underline{18}$ in seiner) Schlichtheit mächtige Johannes ${ }^{82}$.

26 Mehr gilt die Schar der Schlichten [1ㅡ der kunstlos Sprechenden] als (를 die Menge) der gelehrt Redenden. 27 Der Bräutigam [ $\underline{23}$ Christus] nimmt sich von ihnen [늘 den Schlichten] eine zahlreichere Braut $[\underline{25} \text { die Kirche }]^{83} .28$ Auch sehnt er [ ${ }^{26}$ der Bräutigam] sich nicht nach dem [글 beredten] Künstler, sondern nach dem in Schlichtheit Redenden. $\mathbf{2 9}^{84}$ Die Kraft dessen, der das Rechte aussagt und die (Kraft der) Stimme rügt, die grammatisch richtig redet, 30 verurteilt weder Solözismen noch Barbaris$\operatorname{men}^{85}$.

von seinem Ansehen; auch von den Grammatikern wird er angeführt, so zweimal von Priscian. Ein Reflex seiner Geltung ist auch die Anspielung in Hier. epist. 57, 12, 2; hierzu: Bartelink 1980, 111. Zu Aristarchos selber: Pfeiffer 1978, 258-285.

79 Die Aussage, dass Andreas zum einfachen Menschen g e w o r d e n sei (simplex [...] factus), mutet seltsam an; ob allenfalls factus aus Reimgründen gesetzt wurde?

80 Vgl. I Cor. 1, 27. - Die obige Plazierung der beiden Glossen(hälften) nach der Handschrift (vgl. Anm. 11); Egli glaubte sie aus inhaltlichen Gründen nach unten/hinten verschieben zu müssen. Das Bibelzitat ist dem Doppelvers wohl einfach etwas freihändig mitgegeben. Zudem steht in V. 23 fortia robore auf Rasur; der damit konkurrierende Eintrag ut confundat (nicht -et) fortia (über der 1. Vershälfte) dürfte älter sein.

81 Gedacht ist hier an das Herz als Sitz der Gedanken und Empfindungen, doch ist mit pectoris zugleich darauf angespielt, daß Johannes als der Jünger galt, der (nach Ioh. 13, 23.25 und 21, 20) beim Abendmahl an Jesu Brust lehnte; schwach wird auch das Bild des an der Mutterbrust gestillten Kindes erweckt (ausgeprägter: Ekkeh. IV. bened. I 4, 6f.).

82 pincernare als Tätigkeit des Evangelisten Johannes auch bei Ekkeh. IV. bened. I 4, 4.

83 his bezieht sich (zufolge Synesis des Numerus) auf den Kollektivbegriff manus; numerosam als Beiwort zu sponsam zielt unmittelbar auf deren Deutung als Kirche.

84 V. 29 ist nachgetragen; das damnat von V. 30 hätte sich sehr gut auch auf das vorangegangene sponsus beziehen können.

85 rectiloquax - vielleicht eine Wortschöpfung Ekkeharts an Ort und Stelle - bezieht sich, wenn ich recht sehe, (substantivisch) auf vis (entsprechend in V. 28 loquacem), somit auf den, welcher der Sache nach das Richtige sagt. (Dagegen bezieht sich in V. 20 rectiloquo auf den Vertreter der Sprachrichtigkeit.) Zu grammatice vocis ist wohl vim als Objekt zu reprobans aus dem Zusammenhang zu ergänzen. Verstöße gegen die Sprachrichtigkeit bleiben ohne Tadel. Genannt werden die in der grammatischen und rhetorischen Theorie üblichen Termini für sprachliche Verstöße: barbarismus betrifft solche in Einzelwörtern, soloecismus in Syntagmen. Vgl. etwa Lausberg 1990, § 470 und 
31 ${ }^{86}$ Die Schlichtheit der Ausdrucksweise [ ${ }^{\text {Egli S. } 2131}$ betreffs der Wörter oder Sätze] ist von den Hebräern [ $2 \underline{2}$ durch die Übersetzer] den Griechen übermittelt worden. 32 Sie sagt durch diesen Vorzug [ ${ }^{3}$ der heiligen Einfalt $\left.{ }^{87}\right]$ auch den gottesfürchtigen Lateinern zu. 33 Auch hat der Übersetzer ( ${ }^{4}$ diese Worte) nicht verunstaltet, welche der Heilige Geist [ $\left[\underline{5}\right.$ in seiner taubenhaften Schlichtheit $\left.{ }^{88}\right]$ geheiligt hat, $\mathbf{3 4}$ wie aus dem, was in der Genesis und in den Evangelien niedergeschrieben ist, hervorgeht, $\mathbf{3 5}^{89}$ was sie als Hebräisches den Griechen, als Griechisches den Lateinern übermitteln. 36 Wenn Cicero dies läse, wäre es ihm vielleicht gefällig zu schlafen, $37^{90}$ weil ja unsere Rede für ihn schwerer zu ertragen ist, als für uns die seine.

38(f.) Aber es erweist auch jeder [ $\left[\underline{6}\right.$ bezieht sich auf Übersetzer $\left.{ }^{91}\right]$ Übersetzer der Kirche den Priscian ${ }^{92}$ als nutzlosen Künstler; 39 Hieronymus legt Gewicht darauf $\left[{ }^{7}\right.$ stellt es mehr als alle anderen heraus].

40 Mag jener [ ${ }^{8}$ Priscian] fodi sagen, so hat die getreue Übersetzung fodir ${ }^{93}{ }^{2}{ }^{9}$ der getreue Übersetzer, wie Boethius sagt: „damit ich nicht die Schuld des getreuen

passim. Diese Antipoden gepflegter Latinitas werden im christlichen Verweigerungsdiskurs immer wieder genannt. Die Form barbaraismos (vgl. vorher fünfsilbiges soloecismos) ist eine Konzession an das Metrum; das Wort wäre sonst im Hexameter unbrauchbar.

86 V. 31(-56): Beischrift: Pensum für den Lehrer.

87 Die Wortprägung sancta simplicitas findet sich in Rufins Übersetzung der Kirchengeschichte des Eusebius, bei Augustin, Cassiodor, Beda und Späteren. Vgl. aber insbesondere Hier. epist. 57, 12, 4, CSEL 54, S. 525, 17-526, 1: Nec reprehendo in quolibet Christiano sermonis inperitiam [...], venerationi mihi semper fuit non verbosa rusticitas, sed sancta simplicitas: qui in sermone imitari se dicit apostolos, prius imitetur in vita. Vgl. Bartelink 1980, 116f.

88 Nebst der Vorstellung von der Geisttaube (Matth. 3, 16 usw.) ist auch an Matth. 10, 16, estote [...] simplices sicut columbae, zu erinnern.

89 Dieser Vers ist später eingeschoben worden.

90 Dieser Vers ist an die Stelle eines getilgten getreten.

91 Das entsprechende Wort (quicumque) ist im lateinischen Text von dem für ,Übersetzer` weit entfernt.

92 Egli verweist hierzu auf die bekannte, reich glossierte irische St. Galler Priscianhandschrift 904. Aber die Kenntnis Priscians darf bei damaligen Gebildeten gleich Ekkehart ohnehin vorausgesetzt werden; außerdem dient hier sein Name lediglich als Chiffre für Sprachrichtigkeit (ganz wie derjenige Donats in V. 15). Das erhellt nur schon daraus, dass sich Hieronymus (um 347-419) gegen ,Priscian“ (Ende 5./Anfang 6. Jh.) gewandt haben soll.

$93 \mathrm{Zu}$ dem (seit dem Altlatein belegten) fodire statt fodere (4. statt 3. Konjugation, auch bei den Komposita, vgl. frz. fouir): Stotz 1996-2004, 4, VIII § 108.2; Stotz 2011a, 22. 68. Schon Egli (zur Stelle) bringt Materialien bei. - Wieso fodiri eine „getreuere“ Übersetzung sein soll als fodi, wird zunächst nicht klar. Doch der Sache nach könnte sich Ekkehart hier auf eine Äußerung Ermenrichs in seinem Brief an Grimald (überliefert in der St. Galler Handschrift 265) stützen, wonach sich bei Matth. 24, 43 anhand von perfodiri (statt perfodi) erweise, dass die (göttliche) auctoritas die ratio überwinde (Ermenr. ad Grim. 11, ed. 2008, 86f., und Stotz 2011a, 20. 68). Dass Ekkehart hier die Vorsilbe perweglässt, entsprach metrischer Notwendigkeit. Es lässt sich vermuten, dass auch bei ihm, trotz 
Übersetzers auf mich lade“; war er doch ein getreuer Übersetzer des Aristoteles; diese Schuld trägt er in seinen Kommentaren $\left.\mathrm{ab}^{94}\right] ; 41$ sie $\left[\frac{10}{10}\right.$ die getreue Übersetzung] wiegt gegen gelehrtes Studium die erwünschte Schlichtheit auf [ 11 macht ähnlich] [를 Erkunde durch Lesen bei Josephus die Beredsamkeit seiner Genesis und bei Hieronymus die Schlichtheit unserer Genesis und mach so die Probe auf das, was ich sage ${ }^{95}$.] 42 und sie ist bestrebt, den Dingen nach ihrem Gewicht, nicht nach ihrer Zahl gerecht $\mathrm{zu}$ werden. $\left[\frac{13}{3}\right.$ Lies bei Cicero ${ }^{96}$ oder bei Hieronymus, in De optimo genere interpretandi $i^{97}$ nach.] 43 Mag dieser ructuat lesen [ [gli S. $2141 \mathrm{zu}$ lesen anweisen], so die getreue Übersetzung ructat ${ }^{98} .44$ Wenn (를 dieser) angustat liest, soll sie [ ${ }^{3}$ die

allem traditionellen Reden vom fidus interpres, der Gedanke eigentlich doch mehr auf die christliche fides (und deren einfache Ausdrucksweise) geht.

94 Boeth. in Porph. comm. sec. 1, 1, CSEL 48, S. 135, Z. 5-8: Secundus hic arreptae expositionis labor nostrae seriem translationis expediet, in qua quidem vereor, ne subierim fidi interpretis culpam, cum verbum verbo expressum comparatumque reddiderim. Mit fidus interpres knüpft er an Hor. ars $133 f$. an: Nec verbum verbo curabis reddere fidus/interpres. Zur Diskussion der Boethiusstelle: Marti 1974, 66. 87. Ekkehart richtet hier den Blick allerdings auf die Aristotelesübersetzungen. Wer im Sinne der Treue völlig wörtlich übersetzt, lädt gegenüber dem Werk eine Schuld auf sich, die er jedoch durch die Beigabe eines Kommentars abtragen kann - damit tröstet sich auch der Urheber des vorliegenden Versuches!

95 Zunächst sind die Formen sui und nostri auffällig: Sind sie für genitivische Substantive zu nehmen, oder behandelt Ekkehart genesis etwa als Maskulinum (ein Beleg hierfür in MLW 4, Sp. 660, 2)? Der Sache nach nimmt Ekkehart Bezug auf die Antiquitates Iudaicae des Josephus († um $100 \mathrm{n}$. Chr.), worin dieser (Ant. Iud. 1, 27-2, 198) den Stoff der Genesis nacherzählt. In seinem Liber Benedictionum verweist er viermal auf einzelne Stellen dieses Werks: Ekkeh. IV. bened. I 18, 47 (Glosse 5); 21, 57 (14); 26, 46 (16) und 27, 50 (19). An Ort und Stelle geht es ihm um die Gegenüberstellung der schriftstellerisch aufbereiteten Darstellung des Genesisstoffes und der schlichten Wiedergabe des biblischen Urtextes durch Hieronymus. Ekkehart bedient sich offensichtlich der aus dem Umkreis Cassiodors stammenden lateinischen Übersetzung aus der Mitte des 6. Jahrhunderts (Cassiod. Ios. antiqu.). Die ersten fünf Bücher sind in einer modernen Edition greifbar: The Latin Josephus 1958.

96 Gemeint ist die Cicero beigelegte (heute für unecht gehaltene) Schrift De optimo genere oratorum (Cic. opt. gen.), welche Ekkehart zugänglich war; wohl näherhin §§ 14 und 23 (so nach Egli).

97 In der Schrift De optimo genere interpretandi (Hier. epist. 57), bei deren Titel sich Hieronymus an die obige ciceronische Schrift anlehnte (Bartelink 1980, 25), ist die Verteidigung des sinngemäßen Übersetzens gegenüber der Forderung strengster Wörtlichkeit der Inhalt der eigentlichen Kernpartie, Kap. 5 (bis 9).

98 In der Übersetzung verschwindet ein Doppelsinn: fida translatio kann die getreue oder aber die dem Glauben gemäße Übersetzung bedeuten. Das Wort eructare (,herausrülpsen` o. ä.), volkssprachlicher Herkunft (nach erugere), meint in biblisch-bibelnaher Sprache ,durch Rede hervorbringen', etwa in Psalm 44/45, 2 oder 118/119, 171; vgl. Stotz 1996-2004, 2, V § 8.3. Formen mit ructua- könnten mit dem Verbalsubstantiv ructus, -us zusammenhängen; vgl. ebenda 3, VII § 60.2. In klassischer Zeit, und so auch in den Grammatikertexten, überwiegen die Formen auf -ta-. Wie Ekkehart zu der Ansicht kommt, die Formen auf -tua- seien die von der Norm vorgeschriebenen, bleibt dunkel. Bei Priscian jedenfalls (ille, nach V. 38) findet sich (e)ruct(u)are in keiner der beiden Lautungen; wiederum zeigt sich: ,Priscian“ ist hier eine bloße Chiffre. In der Vulgata kommt nur das Kompositum eructa(re) vor; wenn Ekkehart hier mit dem Simplex ruct- arbeitet, dient das wohl 
getreue Übersetzung, weil gerade das, wie Primasius sagt ${ }^{99}$, auch dort verdorben war in der heiligen Einfalt der Schreiber] mit angustiat dagegenhalten ${ }^{100} .45$ Und mag dieser [ ${ }^{4}$ Priscian] in medio duum lesen, so sie [ ${ }^{5}$ die Übersetzung] duorum ${ }^{101}$. 46 Mag die Grammatik missae ( $\underline{6}$ zu lesen anweisen), so soll der Diakon doch ( ${ }^{7}$ ite) missa est singen ${ }^{102} .47$ Die Form melotis [ํㅗ „sie zogen in härenen Gewändern umher“ (circuierunt in melotis $\left.{ }^{103}\right]$ findet der Glaube für gut, mag ihm [ ${ }^{8}$ Priscian] auch melotibus richtig scheinen.

lediglich der Versbequemlichkeit. Formen auf ructu- sind erst aus später Zeit belegt; solche auf eructua- begegnen als Varianten, sodann in der Vet. Lat. und bei christlichen Schriftstellern; vgl. ThLL 5, 2, 825, 25-35.

99 Die Rede ist von Primasius, Bischof von Hadrumetum (550/560). Sucht man in Primas. in apoc. (nebst Ps. Primas. in Rom.) nach Formen von angust(i)are, stößt man auf Primas. in apoc. 2, 7, CCL 92, S. 118, Z. 274f.: Huius beatitudinis fida promissione securi non angustantur, sed cum apostolo dicunt: ,Cor nostrum dilatatum est', et psalmo concinunt: ,Viam mandatorum tuorum cucurri, cum dilatares cor meum‘. Doch vielleicht hatte Ekkehart eine allgemeinere Äußerung im Blick. Zu sancta simplicitas siehe oben, Anm. 87. Was mit der Glosse insgesamt gemeint ist, bleibt einstweilen dunkel. (Die Gen. pl.-Form scriptorum könnte außer zu scriptor auch zu scriptum gehören.)

100 Von angustus, eng' wurde schon zeitig ein Verb angustare ,verengen' abgeleitet, daneben erscheint in der Spätantike, vor allem in christlichen Texten, ein (auf angustia ,Enge') zurückgehendes angustiare ,bedrängen, ängstigen'. Dieses erkennt Ekkehart als eine biblisch-christliche Vokabel, was es (im Wesentlichen) auch ist. Eine andere Äußerung Ekkeharts (siehe Anhang II) zeigt, dass er eine liturgische Anwendung von Sap. 5, 1, adversus eos qui se angustiaverunt, im Blick hat; an dieser Bibelstelle ist allerdings -taverunt die gut bezeugte Textlesart. Weitere Vulgatastellen, an denen die Überlieferung gespalten ist: Sir. 16, 28; 27, 2; Hebr. 11, 37.

101 Neben der seit dem Altlatein gültigen Gen. pl.-Form duorum/duarum gab es die ältere Sonderform duum (vgl. Leumann 1977, 485f.). Zu (in) medio duorum vgl. Ex 25, 22: supra [...] medio duorum cherubin; Zach. 6, 1: de medio duorum montium. Was Priscian betrifft, so benützt er zwar zehnmal die Form duum (in der Regel mit Neutra: generum, temporum). Er stellt die Gen. pl.-Form duorum als die übliche hin, räumt allerdings ein: quamvis in neutro differentiae causa, duum' soleat dici (Prisc. gramm. 2, S. 310, 19-21) - natürlich nur als Möglichkeit, nicht als Regel (bei ihm selber duorum bei Neutra: ebenda S. 53, 3; 126, 18). Ekkehart wittert hierin jedoch einen Angriff auf die Bibelsprache, den es abzuwehren gelte.

102 Nun wendet sich Ekkehart gegen die Verwendung der Pluralform missae, ihr stellt er den Entlassungsruf ite, missa est am Schluss der Messe gegenüber. Indessen waren zur Bezeichnung der Messe selber pluralische Ausdrücke wie missarum sollemnia und dergleichen höchst üblich (NGML M/N, Sp. 618, 7-49, usw.). Und ohnehin wäre nicht einzusehen, wieso die paganen Grammatiker den Christen zum Gebrauch von deren eigener Terminologie hätten Vorschriften machen sollen. Zu missa(e) vgl. Stotz 1996-2004, 2, V § 4.4 (und die in 5, S. 815a angegebene Literatur).

103 Hebr. 11, 37. - Das griechische meloté ,Schaffell, rauhes Fell' ist im biblisch-patristischen Latein als melota (für das härene Mönchs- oder Pilgergewand) gebräuchlich geworden; auch Formen nach der 3. Deklination (Nom. sg. melotes, -tis) kommen vor (vgl. Stotz 1996-2004, 1, IV § 10.13). Die Dat./Abl. pl.-Form melotibus, die Ekkehart ,Priscian' unterschiebt, scheint jedoch wenig gebräuchlich gewesen zu sein. Immerhin findet sie sich etwa in der Wiedergabe der Hebr.-Stelle in Libri Karol. 3, 16, ed. Freeman S. 408, 19. 
48 Mag es Eutychius zukommen, frudat, so dem Glauben, fraudat zu sagen ${ }^{104}$. 49 Je-


singen [ ${ }^{3}$ Dabei ist die Silbe iu lang.], 50 und ich halte es für ihr [ ${ }^{4}$ der Einfalt des Glaubens] unangemessen, beim Singen nach dem gewohnten Metrum [ $\frac{5}{5}$ wonach iu kurz ausgesprochen wird] zu artikulieren ${ }^{105}$.

51 Zwar habe ich nur wenige ( $\underline{6}$ Worte) $[\underline{7}$ beispielshalber] hergesetzt, aber tausenderlei [ ${ }^{9}$ Ähnliches] lässt sich [ ${ }^{8}$ für den, der vorliest] erwähnen ${ }^{106} .52$ Die Gesänge Gregors [ ${ }^{10}$ die untrüglich bekunden, was er gemeint hat, wie duorum und anderes] mögen bewirken, dass das, was ich singe, erhärtet wird, $53^{107}$ tritt in ihnen doch zutage, was der Geist seinem $\mathrm{Ohr}^{108}$ eingesungen hat.

54 Derartiges sei mir trotz den jüngeren Autoren denn doch erlaubt, 55 deren törichter Sinn, von der Sprachlehre ${ }^{109}$ Donats bestärkt, $\mathbf{5 6}$ allein das Eine nicht weiß: dass

$104 \mathrm{Zu}$ fraus ,Betrug' ist eine altlateinische Nebenform frus in einem alten Gesetzestext und zweimal bei Lukrez bezeugt, auch bei dem abgeleiteten Verb fraudare sind Formen auf - $u$ - in den Handschriften vertreten (ThLL 6, 1, Sp. 1266, 80-82 bzw. 1261, 74-76). In der Grammatik des Priscianschülers Eutyches - bei Ekkehart heißt er -chius - kommt fraudare dreimal vor (Eutych. gramm. V S. 459, 1; 471, 8; 485, 30f; Varianten sind dazu nicht aufgeführt). Dieser Text ist in der St. Galler Handschrift 882 (2. Hälfte 9. Jh, S. 67-82. 115-130. 83-111) überliefert. Aber auch hier stehen an allen drei Stellen (S. 115, 17; 88, 8; 107, 13) normale Formen auf frau-. Wie Ekkehart zu der abwegigen Ansicht gelangt, als Normalform werde frudat gefordert, wäre noch zu klären.

105 Ekkehart verteidigt die Perfektform iŭvavi(sse) gegenüber dem regulären Dehnperfekt iūvisse, für das er sich auf eine bestimmte Stelle bei dem Vergilkommentator Servius (anfangs 5. Jh.) beruft: Serv. Aen. 1, 203. Zu dem seit der Kaiserzeit reichlich belegten (ad)iuvavi(sse) und -at(us) an sich: Stotz 1996-2004, 4, VIII § 112. 1. Beim Kirchengesang befürwortet Ekkehart die Längung der Stammsilbe auch bei der -visse-Form, was freilich der überkommenen Prosodie - die er selber einhält widerspricht. Vgl. Anhang II mit Anm. 128.

106 Nachdem Ekkehart zum Schluss eine - angebliche - Eigentümlichkeit des Gregorianischen Gesanges namhaft gemacht hat, setzt er, mit dem von ihm so oft praktizierten hyperbolischen mille, $\mathrm{zu}$ einer Verallgemeinerung an: Noch tausend Eigenheiten der christlichen Sprache würden sich beibringen lassen - und würden sich an den Gesängen Gregors nachweisen lassen. Und weil diese für durch den Heiligen Geist inspiriert galten (siehe unten), sollten denn auch all die vielen - echten oder angeblichen - Anomalien des christlichen Lateins für unmittelbar gottgewollt gelten. Dies ein Beleg für die mittelalterliche Tendenz, auch in inner-lateinischen Spracherscheinungen unmittelbar Gottes ordnendes Walten festmachen zu wollen; vgl. Stotz 2011a, S. 19-22 passim. - In Ekkeharts Aufzeichnung in der St. Galler Handschrift 279 (siehe Anhang II) finden wir gewissermaßen das Rohmaterial zu dem in den vorstehenden Versen Entwickelten.

107 Dieser Vers ist als Ersatz für einen andern nachgetragen worden.

108 Die Form aure steht hier gewiss für den Dativ; gedacht ist an die Geisttaube, die auf Gregors Schulter sitzt und ihm die Worte und Gesänge eingibt.

109 Für grammate erwog Ekkehart als Alternative dogmate - Egli wollte darin Stabreim erkennen -, verwarf sie aber wieder. 
der die gewaltigen Kräfte des Glaubens [ 11 die Fähigkeiten von dessen heiliger Einfalt] nicht kennt ${ }^{110}$.

$57^{111} \mathrm{Zu}$ der Zeit, als die Kirche auf sich selber einen Geschosshagel niedergehen ließ inmitten dessen, was da aufgekommen war $[\underline{12}$ indem die wahre mit der halbwahren (Kirche) rang], 58 hat es schweren Schaden gestiftet [ ${ }^{\text {Egli }}{ }^{2} .2161$ hat es sehr gescha$\operatorname{det}^{112}$, dass die Irrlehren [ ${ }^{2}$ die Irrlehrer] sich mit dreifacher Kunst [ ${ }^{3}$ mit der Grammatik, der Dialektik und der Rhetorik] des Glaubens ${ }^{113}$ bemächtigten. 59 ( ${ }^{5}$ Mit ebendiesen drei) Künsten galt es ( ${ }^{4}$ durch die Gläubigen) Widerstand zu leisten und galt es danach zu streben, 60 dass die Schlangen ${ }^{114}$ [ ${ }^{\underline{6}}$ die Irrlehrer] gegenüber dem Glauben und seine $[\underline{\underline{8}}$ verschiedenartigen] Feinde durch sie $[\underline{7}$ durch ebendiese Künste] überwunden würden, 61 welche [ ${ }^{9}$ nämlich die Feinde] die kunstvoll $[\underline{10}$ vor allem mit der dialektischen Kunst] redenden Plato und Aristoteles beleben, 62 damit, ( 11 wenn) Arius mit ihrer $\left[\underline{\underline{12}}\right.$ der Künste] Hilfe wütete [ $[\underline{13} \text { ohne alle Vernunft handelte }]^{115}$, Athanasius [ $\left[\frac{14}{}\right.$ der sich durch sein Glaubensbekenntnis ${ }^{116}$ als tiefgläubig erweist] damit die Oberhand gewinnen könne, 63 ( $\frac{15}{15}$ und damit) die gegnerische Kunst [ 16 die Verkehrtheit der Irrlehren] mit gleicher Waffe vernichtet werden könne.

64 Diese verhöhnen, um die Fischer [ ${ }^{17}$ solche: Petrus, Johannes, Andreas] ihre Ehre [ ${ }^{18}$ der Einfachheit ihrer Rede] verlieren zu lassen, 65 hochfahrend in ihren Künsten, die Einfalt [ ${ }^{19}$ unserer Ausdrucksweise, nämlich die der Kirche]. 66 Während sie [을 beide ${ }^{117}$ : die Gläubigen und die Irrgläubigen] Derartiges erlernen und zweifachen

110 Mit Gregors Autorität im Rücken wendet er sich gegen jüngere, vielleicht karolingerzeitliche Grammatiker im Fahrwasser Donats. Im Frühmittelalter war die vielleicht wichtigste Art, den Grammatikstoff zu behandeln, die Kommentierung von dessen Ars minor und maior. Mit einer Pathosformel wirft er ihnen vor, die Kraft des Glaubens zu verkennen. Angesichts dessen, dass er selber sich eines korrekten, wo nicht gar preziösen Lateins befleißigt, wirkt sie etwas theatralisch.

111 Dieser Vers ist als Ersatz für einen andern eingetragen worden. - Zu V. 57(-71) die Beischrift: Dichtung eines Tages. - In dem hier beginnenden Absatz wandelt sich Ekkeharts Gedanke: Während er sich vorher gegen die überkommenen sprachlichen Fertigkeiten abgegrenzt hat, stellt er jetzt diese selber als der Kirche dienendes Mittel zur Abwehr der in ihnen beschlagenen Häretiker hin.

112 Die Glosse gilt einzig der ungewohnten Präfigierung pernocuit, was in der Übersetzung nicht sichtbar gemacht werden kann. Belege für das erst nachantik bezeugte und selten gebliebene Wort in NGML P 2, Sp. 621, 31-36; DBrit S. 2222c.

113 fidei dürfte zunächst als Genitivobjekt zu potiri aufzufassen sein, könnte jedoch, rein formal, auch Dativobjekt zu pernocuit sein.

$114 \mathrm{Zu}$ dem von Ekkehart verwendeten prestis: Stotz 2011b, 336 mit Anm. 93.

115 Eine weitere Gegenüberstellung von Arius und Athanasius: Ekkeh. IV. bened. I 57,24 (vgl. dort V. 27. 42); in 2, 33 erwähnt er dessen unheilsschwangere Geburt.

116 Das so genannte athanasianische Glaubensbekenntnis (nicht von Athanasius, sondern aus der Westkirche stammend) wird durch seine Eingangsworte Quicumque vult salvus esse [...] bestimmt.

117 utrique, nicht virique (siehe Anm. 11). 
Scharfsinn [ ${ }^{21}$ den der wahren Logik und der Sophistik] erkennen, 67 erbaut die

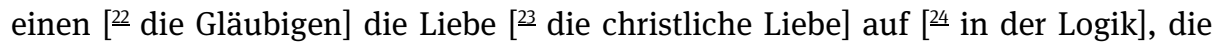
andern [ ${ }^{25}$ die Irrlehrer] macht ihre weitläufige Weisheit [ ${ }^{26}$ in der Sophistik] aufgeblasen [ $[\underline{27} \text { hochfahrend }]^{118}$.


gleicher Weise [ $\underline{30}$ in diesen Künsten] unterrichten zu lassen, 69 erproben wir sehr Vieles, wir lieben das, was die Vernunft [ ${ }^{31}$ gemäß der wahren Logik] betrifft, 70 und verehren doch noch mehr [ ${ }^{32}$ als ${ }^{119}$ die Künste der gefährlichen Beredsamkeit] die uns willkommene Einfachheit $\left[\frac{33}{3}\right.$ in welcher keine Gefahr liegt], 71 über welche Paulus nicht errötete, und die Petrus selber guthieß $\aleph^{120}$.

$\mathbf{7 2}^{121}$ Die reine Einfalt, wem [34 welcher Tugend] könnte sie nachstehen? 73 Ihre ( 35 vielfältigen) Vorzüge und heilsamen Wirkungen dürfte niemand nach Gebühr benennen ( ${ }^{36}$ können). 74 Sie [ ${ }^{37}$ die Einfalt] verleiht mitunter, dass Unvollkommene vollendet sein können. 75 Dich, Petrus, haben die Augen Christi als Unvollkommenen erblickt: 76 (die Augen) dessen, dem all das wohlgefällig ist, was niedrig ist und ( 38 was) sich ( 39 selber) gering ( $\left(40\right.$ vorkommt). 77 Er, der als Kindlein ( ${ }^{41}$ in) einer krippenartigen Wiege liegt [ ${ }^{42}$ während ihm eine goldene gebührt hätte], 78 ist, der König von ewiger Majestät, in Windeln gewickelt [ ${ }^{\text {Egli }}$. 2171 während ihm Purpur gebührt hätte], 79 er, der auf der Flucht durch sein Schreien den Herodes verdammt, 80 und der als Schaf vor dem Wolf als armer Flüchtling Canopus [르gypten] aufsucht. 81 Der hohe Gott hat sich ausersehen, was niedrig ist, und hat das Hohe zu Fall gebracht; 82 er stärkt das Schwache und macht das, was seinem Aussehen nach [ 3 zu Unrecht] stark ist, zuschanden. $83 \mathrm{Ihm}$ sei Lob und Dank allezeit und über die Zeit hinaus [ ${ }^{4}$ auf ewig].

118 Damit ist auf I Cor. 8, 1 angespielt: scientia inflat, caritas vero aedificat.

119 quam, nicht qua (siehe Anm. 11).

120 Hierzu verweist Egli auf II Cor. 1, 12 bzw. I Petr <5>, 5 f.

$121 \mathrm{Zu} \mathrm{V.72(-83)} \mathrm{Beischrift:} \mathrm{Geschuldetes} \mathrm{Tagespensum.}$ 


\section{Anhang: Zwei weitere Äußerungen Ekkeharts zur Diskurstradition der Absage an die Sprachrichtigkeit}

\subsection{Das Zeugnis in der St. Galler Handschrift 159}

In der St. Galler Handschrift 159, die in ihrem ersten Teil (Mitte 9. Jh.) vierzig Briefe des Hieronymus enthält, lesen wir auf S. 13 - zu den Worten: Mihi sufficit sic loqui, ut intellegar et ut de scripturis disputans scripturarum imiter simplicitatem ${ }^{122}-$ am Rande folgende Beischrift Ekkeharts, die gleichsam die Quintessenz der Confutatio grammaticę darstellt123:

Ecce his Hieronimi verbis conveniendi sunt, qui ęcclesiam arguunt ,angustiati‘ (vgl. V. 44), perfodiri‘ (V. 40), ,defraudavi` (V. 48) et mille talia extra regulam usurpare, cum etiam Gregorius eadem sentiens scripturas sanctas ,oracula' nominet, eo quod et in fanis deorum oracula nullam umquam tenuissent grammaticę derivationem. Ait enim ipse ille, cuius in aurem columba rostro inseruit dictanda (V. 53): „Eloquium divini oraculi non stringitur regulis Donati.“"124 $\mathrm{Ne}$ que enim piscatores illi (V.3f. 17. 64) a Bethsaida (V.16-21), quamvis igneis linguis sint usi (vgl. Act. 2, 3f.), urbanius docuerant ad literam, quam domi didicerant. Legamus Paulum (V. 715. 22f. 71) ad Romanos tonitruis simplicitatis fulgurantem contra inanem sęculi facundiam.

(,Mit diesen Worten des Hieronymus sind die zu tadeln ${ }^{125}$, welche die Kirche dafür schelten, dass sie angustiati, perfodiri, defraudavi und tausend ähnliche regelwidrige Dinge in Gebrauch habe, wo doch auch Gregor, der gleich denkt wie er, die Heiligen Schriften ,heilige Aussprüche‘ nennt, und zwar deshalb, weil auch in den Heiligtümern der Götter die heiligen Aussprüche niemals dem folgen, was sich aus der Sprachlehre ergibt. Hat doch gerade er, in dessen Ohr die Geisttaube mit ihrem Schnabel eingegeben hat, was er diktieren solle, gesagt: ,Die Sprechweise göttlicher Rede lässt sich durch die Regeln Donats nicht in die Schranken weisen. 'Und es haben ja auch jene Fischer aus Bethsaida, wenn sie sich gleich feuriger Zungen bedient haben, ihre Lehren dem Wortlaut nach nicht gepflegter ausgedrückt, als sie es zu Hause erlernt hatten. Lesen wir, wie Paulus im Römerbrief mit Blitz und Donner seine einfache Rede der eitlen Beredsamkeit der Welt entgegensetzt.“)

Originell scheint mir Ekkeharts Gedanke zu sein, Gregor der Große habe in dem anzitierten Ausspruch - der von ihm und andern wohl weit überschätzt worden ist mit (bildungsapologetischer) Absicht das Wort oraculum verwendet, um die chris-

122 Hier. epist. 36, 14, 2, CSEL 54, S. 280. 281, 2f.; zu dem ganzen Passus vgl. Marti 1974, 89.

123 Gedruckt von Egli in Ekkehart, Liber Benedictionum/Egli 1909, 215; zu Nr. 42, V. 55 (angustiari in -iati zu verbessern, nulla in -am). Vgl. das Verzeichnis der Handschriften mit Einträgen Ekkeharts bei Eisenhut 2009, 420.

124 Vgl. Greg. M. moral. epist. 5, CCL 143, S. 7, Z. 220-222: indignum vehementer existimo, ut verba caelestis oraculi restringam sub regulis Donati. Hierzu etwa Stotz 2011a, 19.

$125 \mathrm{Zu}$ so gebrauchtem convenire: MLW 2, Sp. 1813, 18-22. 
tensprachlichen Anomalien mit dem Hinweis auf archaische (u. ä.) Sonderformen paganer Sakralsprache gewissermaßen zu rechtfertigen.

\subsection{Das Zeugnis in der St. Galler Handschrift 279}

In der St. Galler Handschrift 279 (2. Hälfte 9. Jh.), enthaltend den ersten Teil der ,Collectanea ex Augustino in epistolas Pauli“ des Florus von Lyon († um 860), lesen wir auf S. 424 - zu den Worten: Unde plerumque loquendi consuetudo vulgaris (Glosse: id est villana rusticitas) utilior est significandis rebus (Glosse: scilicet divinis) quam integritas litterata [... $]^{126}$ - am Rand den folgenden Eintrag ${ }^{127}$ :

Nota Augustinum simplicitatem locutionis de Bethsaida piscatorum malle quam urbanitatis leporem et facundiam forensem, cum oracula fidei repudient regulas Donati Gregorio teste: ,duorum‘ (vgl. V. 45), ,adiuvata‘ (V. 49), ,eructavit‘ (V. 43), ,qui se angustiaverunt‘ (V. 44) et mille talibus, quę melodia solvi non patitur, etiam si nudis verbis contradicatur.

(„Merke dir, dass Augustin die einfache Ausdrucksweise der Fischer von Bethsaida der gepflegten Eleganz und der Beredsamkeit eines Redners vor Gericht vorzieht, da ja die Aussprüche des Glaubens die Regeln Donats zurückweisen, wovon Gregor Zeugnis ablegt mit duorum, adiuvata, eructavit und qui se angustiaverunt, und mit tausenderlei Dingen dieser Art, bei denen die Melodie nicht geändert werden kann, auch wenn den Worten an sich Widerspruch erwächst.“)

Hier klingt die oben evozierte, allgemein gehaltene Stelle bei Gregor nur schwach an, dafür wird dieser auf andere Weise als Zeuge aufgeboten, nämlich durch den durchweg auf ihn persönlich zurückgeführten - gregorianischen Gesang. Vier Stellen werden, je neumiert, angegeben, bei denen die Wortform durch die Neumen entgegen der - vorausgesetzten - Sprachrichtigkeit verbürgt sei ${ }^{128}$. Der Wortlaut der Gregorianischen Gesänge ist nach dieser Sicht durch die Melodie gesichert, die für gleichfalls göttlich inspiriert galt. Im Einzelnen lässt sich dazu Folgendes bemerken: Duorum stammt aus dem Vers In medio duorum innerhalb des Graduale Domine audivi (AMS 78). Ekkeharts Neumierung stimmt mit dessen Niederschrift in der mit ihm zeitgenössischen St. Galler Handschrift 376 (S. 188, Feria VI in Parasceve [Karfreitag]) überein. Das Wort adiuvata findet sich in dem Responsorium Ego autem

126 Aug. doctr. christ. 3, 3, Z. 43-45, CCL 32, S. 81.

127 Gedruckt von Egli in Ekkehart, Liber Benedictionum/Egli 1909, S. 212, zu Nr. 42, V. 15; vgl. Eisenhut 2009, 422.

128 Alle folgenden Angaben gehen zurück auf Mitteilungen von Herrn Kollegen Michael Klaper, Institut für Musikwissenschaft Weimar-Jena, und von meinem Freund Rudolf Stäuble, Winterthur, denen ich für ihr Interesse und ihre liebenswürdige Hilfsbereitschaft herzlich danke. - Noch nicht gelöst ist einstweilen die Frage, woher in der damaligen Gesangspraxis Ekkehart das Beispiel iuvavit (Gedicht 42, V. 49, ohne Neumierung) bezogen hat. Für die Silbe iu- fordert er dort Langmessung; durch den nachstehend für adiuvata beigebrachten Beleg wird dies jedenfalls nicht gestützt. 
adiuvata a Domino zum Fest der heiligen Agatha (CAO 6625). Ekkeharts Neumierung entspricht weitgehend derjenigen in der St. Galler Handschrift 390 (,HartkerAntiphonar‘, S. 123); die melodische Fassung ist dieselbe. Für eructavit, im Offizium und im Messproprium mehrfach vorkommend, kommt der Beginn des Versus Eructavit cor meum im Graduale Speciosus forma als Quelle in Betracht. ${ }^{129}$ Die Wortfügung qui se angustiaverunt ist nur an einer Stelle, und nur in der St. Galler Handschrift 391 (ebenfalls ,Hartker-Antiphonar'), S. 52, bezeugt, dies in der Offiziumsantiphon Stabunt iusti (nach Sap. 5, 1, CAO 5012). Ekkeharts Neumierung stimmt mit der hier vorliegenden, von einem unwesentlichen Unterschied abgesehen, überein.

\section{Literaturverzeichnis}

AMS = Antiphonale missarum sextuplex. Édité par René-Jean Hesbert d'après le graduel de Monza et les antiphonaires de Rheinau, du Mont-Blandin, de Compiègne, de Corbie et de Senlis (1935), Bruxelles.

Bambeck, Manfred (1983), Fischer und Bauern gegen Philosophen und sonstige Großkopfeten - ein christlicher ,Topos“ in Antike und Mittelalter. In: Mittellateinisches Jahrbuch 18, 29-50.

Bartelink, G. J. M. (1980), Hieronymus, Liber de optimo genere interpretandi (epistula 57). Ein Kommentar (Mnemosyne, Supplementum 61), Lugduni Batavorum.

$\mathrm{CAO}=$ Corpus antiphonalium officii editum a Renato-Joanne Hesbert. 6 vol. (1963-1979). (Rerum ecclesiasticarum documenta, Series maior: Fontes 7-12), Roma.

$\mathrm{CCL}=$ Corpus christianorum. Series Latina (1953ff.), Turnholti.

Chase, Michael/Harmon, Roger (2001), Artikel ,Porphyrios‘. In: Der Neue Pauly ..., Altertum 10, Stuttgart, 174-181.

CSEL = Corpus scriptorum ecclesiasticorum Latinorum (1866ff.), Vindobonae.

DBrit $=$ Dictionary of Medieval Latin from British Sources (1975-2013), Oxford.

Eisenhut, Heidi (2009), Die Glossen Ekkeharts IV. von St. Gallen im Codex Sangallensis 621. (Monasterium Sancti Galli 4), St. Gallen.

Ekkehart: Der Liber Benedictionum Ekkeharts IV. nebst den kleinern Dichtungen aus dem Codex Sangallensis 393. Zum ersten Mal vollständig hg. und erläutert von Johannes Egli (1909). (Mitteilungen zur vaterländischen Geschichte, hg. vom Historischen Verein in St. Gallen 31, 4. Folge 1). St. Gallen.

Ermenrich d'Ellwangen, Lettre à Grimald, Texte latin édité, traduit, annoté et introduit par Monique Goullet (2008). (Sources d'histoire médiévale 37), Paris.

Gäbe, Sabine (1999), Otloh von St. Emmeram, ,Liber de temptatione cuiusdam monachi‘. Untersuchung, kritische Edition und Übersetzung. (Lateinische Sprache und Literatur des Mittelalters 29), Bern.

Graduale Novum. Editio magis critica iuxta SC 117 ... Tomus 1, De dominicis et festis (2011), Regensburg.

129 Vgl. die Transkription im Graduale Novum, S. 41f. Die dort eingetragenen Neumen sind dem St. Galler Cantatorium, Hs. 359, S. 45, aus den Jahren 922-925, entnommen. Auch später, zur Zeit Ekkeharts, wird das Eructavit gleich neumiert. Das zeigen die St. Galler Handschriften 339, S. 50 (um 1000), 374, S. 23 (Mitte 11. Jh.) und 376, S. 107 (Mitte 11. Jh.). 
Haag, Herbert (2003), Biblisches Wörterbuch. Sonderausgabe, Freiburg i. Br.

Hagendahl, Harald (1959), Piscatorie et non Aristotelice. In: Septentrionalia et Orientalia. Studia Bernhardo Karlgren dedicata (Kungl. vitterhets, historie och antikvitets academiens handlingar 91), Stockholm, 184-193.

Hurschmann, Rolf (1999), Artikel ,Kreisel‘. In: Der Neue Pauly ..., Altertum 6, Stuttgart, 824.

The Latin Josephus, I: Introduction and text, The Antiquities, books 1-5, by Franz Blatt (1958). (Acta Jutlandica, Aarsskrift for Aarhus Universitet 30, 1, Humanistisk serie 44). Aarhus/København.

Lausberg, Heinrich (1990), Handbuch der literarischen Rhetorik. Eine Grundlegung der Literaturwissenschaft, 3. Auflage, Stuttgart.

Leumann, Manu (1977). Lateinische Laut- und Formenlehre. (Lateinische Grammatik von LeumannHofmann-Szantyr 1; Handbuch der Altertumswissenschaft II 2, 1), München.

Marti, Heinrich (1974), Übersetzer der Augustin-Zeit. Interpretation von Selbstzeugnissen. (Studia et testimonia antiqua 14), München.

MGH $=$ Monumenta Germaniae Historica.

MLW = Mittellateinisches Wörterbuch bis zum ausgehenden 13. Jahrhundert (1959ff.), München.

$\mathrm{NGML}=$ Novum Glossarium mediae Latinitatis (1957ff.), var. loc.

$\mathrm{PL}=$ Patrologiae cursus completus ..., Series Latina ..., accurante J[acques] P[aul] Migne. 221 tomi (1844-1864), Parisiis.

Pfeiffer, Rudolf (1978), Geschichte der Klassischen Philologie. Von den Anfängen bis zum Ende des Hellenismus, 2., durchgesehene Auflage. (Beck’sche Elementarbücher), München.

Rädle, Fidel (1974), Studien zu Smaragd von Saint-Mihiel. (Medium aevum. Philologische Studien 29), München.

Remigii Autissiodorensis Commentum in Martianum Capellam, libri 3-9, edited by Cora E. Lutz (1965), Leiden.

Schauwecker, Helga (1963), Otloh von St. Emmeram. Ein Beitrag zur Bildungs- und Frömmigkeitsgeschichte des 11. Jahrhunderts. In: Studien und Mitteilungen zur Geschichte des Benediktinerordens und seiner Zweige 74, 3-240.

Schulz, Ernst (1942), Über die Dichtungen Ekkeharts IV. von St. Gallen. In: Corona quernea. Festgabe Karl Strecker zum 80. Geburtstage dargebracht (Schriften des Reichsinstituts für ältere deutsche Geschichtskunde [Monumenta Germaniae historica] 6), 199-235.

Stotz, Peter (1981), Dichten als Schulfach - Aspekte mittelalterlicher Schuldichtung. In: Mittellateinisches Jahrbuch 16, 1-16.

Stotz, Peter (1996-2004), Handbuch zur lateinischen Sprache des Mittelalters. 5 Bände. (Handbuch der Altertumswissenschaft II 5, 1-5), München.

Stotz, Peter (2011a), Die Bibel auf Latein - unantastbar? (Mediävistische Perspektiven 3), Zürich.

Stotz, Peter (2011b), Ornamentales Griechisch im mittelalterlichen Latein. In: Influencias léxicas de otras lenguas en el latín medieval ..., Coordinadores: Maurilio Pérez González/Estrella Pérez Rodríguez, Valladolid/León, 319-343.

ThLL $=$ Thesaurus linguae Latinae (1900ff.), var. loc.

The Virgilian tradition (2008). The first fifteen hundred years, Jan M. Ziolkowski and Michael C. J. Putnam, editors, New Haven.

Vogel, Cyrille (1966), Introduction aux sources de l'histoire du culte chrétien du moyen âge. (Biblioteca degli ,Studi medievali‘ 1), Spoleto.

Weber, Stefan (2003), Ekkehardus poeta qui et doctus. Ekkehart IV. von St. Gallen und sein gelehrt poetisches Wirken, Nordhausen. 
